\title{
The Asilomar Survey: Stakeholders' Opinions on Ethical Issues Related to Brain-Computer Interfacing
}

\author{
Femke Nijboer • Jens Clausen • \\ Brendan Z. Allison • Pim Haselager
}

Received: 28 December 2010 / Accepted: 28 July 2011 /Published online: 17 August 2011

(C) The Author(s) 2011. This article is published with open access at Springerlink.com

\begin{abstract}
Brain-Computer Interface (BCI) research and (future) applications raise important ethical issues that need to be addressed to promote societal acceptance and adequate policies. Here we report on a survey we conducted among $145 \mathrm{BCI}$ researchers at the $4^{\text {th }}$ International BCI conference, which took place in May-June 2010 in Asilomar, California. We assessed respondents' opinions about a number of topics. First, we investigated preferences for terminology and definitions relating to BCIs. Second, we assessed respondents' expectations on the marketability of different BCI applications (BCIs for healthy people, BCIs for assistive technology, BCIs-controlled neuroprostheses
\end{abstract}

F. Nijboer $(\bowtie)$

Human Media Interaction, University of Twente,

Enschede, the Netherlands

e-mail: Femke.Nijboer@utwente.nl

J. Clausen

Institute for Ethics and History of Medicine,

University of Tübingen,

Tübingen, Germany

B. Z. Allison

Laboratory of Brain-Computer Interfaces,

Graz University of Technology,

Graz, Austria

P. Haselager

Donders Institute for Brain, Cognition and Behaviour,

Radboud University,

Nijmegen, the Netherlands

e-mail: W.haselager@donders.ru.nl and BCIs as therapy tools). Third, we investigated opinions about ethical issues related to BCI research for the development of assistive technology: informed consent process with locked-in patients, risk-benefit analyses, team responsibility, consequences of BCI on patients' and families' lives, liability and personal identity and interaction with the media. Finally, we asked respondents which issues are urgent in BCI research.

Keywords Brain-computer interfaces · Brain-machine interfaces $\cdot$ Neuroethics $\cdot$ Neuroimaging $\cdot$ Locked-in syndrome

\section{Introduction}

The research field of Brain-Computer Interface (BCI) is growing rapidly. The scientific foundations of BCI research were established decades ago, mostly by medical doctors, neurophysiologists, psychologist and physicists (e.g. [6, 7, 14, 15, 18-20, 33, 34, 67, 70].

Recent contributions from other fields such as humancomputer interaction (HCI), electrical engineering, computer science and artificial intelligence have fostered tremendous innovation in BCI research. This has resulted in a new (additional) focus on non-medical applications (e.g. gaming, military use, and workplace devices). The increasing number of contributors, applications, and users has exposed some controversial topics and potential roadblocks. In particular, researchers and policy 
makers are becoming more and more aware of emerging ethical issues related to $\mathrm{BCI}$ research, development and dissemination. BCIs are also increasingly prominent in popular culture and thus, perceived by the general public. For example, popular TV shows such as House, Star Trek, and Fringe have aired episodes that present BCIs [3]. Media frequently and inaccurately report that science is now capable of reading peoples' thoughts and dreams, even when people are in a vegetative state (e.g.: [1, 11, 21, 46, 65]). However, most BCI researchers described in these articles merely try to obtain a binary signal, a so-called single switch, from a patient to enable control of an assistive technology (AT) device. As long as patients have a single switch, either a residual muscle movement or a BCI-controlled signal, they can use AT [29].

In 2006, Wilhelm and colleagues reported on their attempt to communicate with a complete locked-in patient. Through food imagery, the patient manipulated her salivary $\mathrm{pH}$ and could give yes/no answers to questions [68]. In an accompanying editorial, Phillips responded to this article with the critical question 'even when you can communicate with a locked-in patient, should you do it?" [48]. Phillips argued that the development of Brain-Computer Interfaces for communication might compel physicians and patients to consider life-sustaining treatments more often, and that patients are therefore at higher risk of becoming lockedin. However, the assumption that quality of life in the locked-in state is necessarily low, as suggested by Phillips, is factually wrong [28, 29, 32, 52, 58]. Phillips further argued that life-sustaining treatments might inflict heavy burdens on the quality of life of the patients and the emotional and financial state of the caregivers. Dobkin also suggests that the use/ availability of BCIs as assistive technology might bring financial, physical and emotional burden to persons [13]. Both authors urge BCI researchers to address ethical concerns related to Brain-Computer Interfacing.

Phillips and Dobkin raise important issues that the BCI community should address further. BCI research and future applications do not necessarily have only

\footnotetext{
${ }^{1}$ Nijboer and Broermann, the latter author being a locked-in patient, responded to Philips' question with another question: "When you can communicate with a locked-in patient, why should you not do it?" [42].
}

beneficial consequences, but may also lead to harmful consequences.

The nascent neuroethical debate has identified several topics of importance to Brain-Computer Interfacing: 1) obtaining informed consent from people who have difficulty communicating, 2) risk/ benefit analysis 3) shared responsibility of BCI teams (e.g. how to ensure that responsible group decisions can be made), 4) the consequences of BCI technology for the quality of life of patients and their families, 5) side-effects (e.g. neurofeedback of sensorimotor rhythm training is reported to affect sleep quality) 6) personal responsibility and its possible constraints (e.g. who is responsible for erroneous actions with a neuroprosthesis?), 7) issues concerning personality and personhood and its possible alteration, 8) therapeutic applications, including risks of excessive use, 9) questions of research ethics that arise when progressing from animal experimentation to application in human subjects, 10) mind-reading and privacy, 11) mindcontrol, 12) selective enhancement and social stratification, 13) human dignity, 14) mental integrity, 15) bodily integrity, 16) regulating safety, 17) communication to the media $[4,8,9,17,22,40,53,54,61,63]$.

\section{The Emerging Neuroethical Debate}

However, the results from this initial debate do not seem to be fully integrated into BCI research. BCI researchers, like neuroscientists, may have good reason for their reluctance to wade into ethics. The questions raised are likely to be open-ended, and their arrival in the world both inside and outside the laboratory may be some way off [16]. Furthermore, many BCI researchers come from an engineering background, and may have less training and interest in ethical matters. Finally, BCI researchers may be interested in ethical issues they are confronted with in daily work situations, while some ethicists focus on more abstract, but no less relevant, themes like enacted mind or embodied mind [17, 66]. Additionally, the public community may be more concerned with issues like mind-reading, animal experimentation and military applications. These different viewpoints and interests notwithstanding, we believe it is worthwhile to invite and support the BCI community to articulate its (varying) views as clearly as possible. Obviously, this is not something that can be accomplished in one big swoop, as extracting and clearly 
identifying the opinions of the members of a young, multi-disciplinary research field will take time for thinking about, discussing thoroughly and articulating clearly the ethical issues perceived to be central and/ or most pressing. We therefore submit our work as one of the first incomplete steps in a long-range attempt towards clarifying the views of at least a segment of the BCI research community. Work such as provided here may invite other BCI-researchers to give their thoughts on the ethical issues involved.

During the 4th International BCI Meeting, which took place at the Asilomar conference centre in California, we conducted a survey among the attendees to help assess the views and moral concerns of the BCI community, and lay the foundations for developing BCI research efforts into a more mature effort. After extensive internal discussion and pilot testing, our team developed a twopart survey shown in Appendix I. One portion of the survey focused on the ethical issues that are important for the maturing technology of BCI. The second part of the survey addressed issues such as terminology, criteria for BCI definition, matters of urgency and expected marketability. The 4th International BCI meeting was the largest BCI meeting ever (289 estimated attendees) and provided an exceptional opportunity to explore key issues amongst colleagues, although it has to be noted that many other qualified respondents (e.g. from the field of human-computer interaction or ambient intelligence) do not typically attend this meeting which may have biased our findings (see 'Some thoughts on the survey' in the Discussion). The conference is focused on systems that measure brain signals, extract relevant features from those brain signals and translate them into commands to software or hardware applications. This close community refers to itself as the BCI community, although many other persons use the phrase braincomputer interface also to refer to Deep Brain Stimulation, vagal nerve stimulation or cochlear implants. Thus, it needs to be noted that at this BCI conference only brain-to-computer systems are the center of focus.

\section{What's in a Name?}

Individual assessments of the ethical implications of research and applications in a multi-disciplinary and multi-faceted area as BCI will depend largely on the individual's interpretation on what a BCI is and isn't. For example, someone who excludes certain research directions or applications as not being part of $\mathrm{BCI}$ may be less interested in certain ethical issues than a person with a broader definition. Moreover, the ethical debate will be facilitated with common terminology concerning BCIs, which has proven highly problematic. The first reason for the variance in terminology is that BCIs may have several functions. The term BCI, for example, may be used for a gaming application for healthy users, but also as an assistive technology for a person in the locked-in state. Depending on functions and target users, different ethical issues will arise. A second complication is that some BCIs use invasive recordings from the brain, whereas others use noninvasive recordings. The pervasiveness of the imaging technique used for BCIs may greatly influence the ethical debate, such as when a risk/benefit analysis is made. A third issue consists of whether people consider BCIs an outward-directional (from the brain to the computer/machine) or an inward-directional (from the computer/machine to the brain) interface. Are BCIs systems that measure brain signals and "translate" this input into output signals? Or can a BCI also be a system that uses externally generated input, e.g. Deep Brain Stimulation (DBS), to modify brain activity?

Some articles that discuss ethical issues and BCIs rely on a very broad definition of BCIs. For example, Racine and colleagues investigated media coverage of neurostimulation technologies and other contemporary neuroscience topics and included the terms "brain-machine interface", "brain-computer interface" and "neural prosthesis" in the search for printed media about these topics $[50,51]$. They clearly perceive invasive BCI as examples of neurostimulation techniques (personal communication). Similarly, Demetriades and colleagues recently argued that Brain-Machine Interfaces (BMIs) should solely be used for purposes of medical treatment, and all other applications should be immediately banned as unethical. However, they came to this conclusion because they included the implantation of deep brain stimulation electrodes in the definition of BMIs and focused heavily on risks of mind control that are unrealistic with conventionally defined BCIs [12].

Schermer, who discusses the conceptual and moral implications of Brain-Machine Interaction, also includes cochlear implants, deep brain stimulation in her definition of Brain-Machine Interfaces [54]. Furthermore, she describes, as an example of neurofeedback, a new method for preventing epilepsy attacks with the aid of Vagal Nerve Stimulation (VNS). Changes in brainwaves can be detected and 
used to predict an oncoming epileptic attack. This warning system can then generate an automatic reaction from the VNS system which stimulates the vagal nerve and prevents the attack [54]. This example of neurofeedback need not be considered a typical example by the so-called BCI community.

Apart from terminology, there are other topics that may influence a person's stance on ethical questions. For example, people contributing to the debate may have different opinions on what is currently feasible with BCIs and which commercial BCIs are currently available. Also, they may have different expectations about BCI marketability in the future. Overly optimistic or pessimistic predictions regarding functionality, benefit and marketability of BCI products may have several consequences. First, expectations of marketability of future $\mathrm{BCI}$ products influence the timing and the pace of the ethical debate. Secondly, beliefs about functionality and benefit of BCI products influence the risk/benefit analysis. For example, a locked-in patient may be told during the informed consent procedure that the BCI is "going to bring back his communication skills", whereas realistically the chances are much lower.

Below, we survey ethical opinions of BCI researchers, preferences for terminology and definitions of BCI, and expectations about marketability of BCIs.

\section{Methods}

Pilot Study

A pilot internet survey with 29 items was created to elicit opinions on ethical aspects of BCI research, terminology and matters of urgency. Items consisted of multiple choice questions, open questions and rating scales. The survey was distributed to members of the group of BCI scientists at the Braingain Group of the Radboud University of Nijmegen. Respondents were asked to complete the survey and give feedback on the relevance, quality and quantity of the questions.

The survey assessed 1) demographic information, 2) opinions about terminology and definition of BCIs, 3) opinions about BCI applications for healthy users, 4) for assistive technology, 5) for prosthesis, 6) for therapy tools. The largest part of the survey was about 7) ethical aspects related to BCI research and finally, assessed 8) opinions about urgent issues in BCI research.
Nine BCI researchers (1 female, 8 males), with different degrees of expertise, entered the pilot study. Respondents needed between 15 and $30 \mathrm{~min}$ to complete the survey, which was evaluated as too time consuming. Therefore, we revised the survey such that the time needed to complete the survey was reduced to an estimated maximum of $15 \mathrm{~min}$. Respondents gave constructive criticisms to the questions, so that we revised items to be more concise. From the data we could see variance in the answers, which supported the notion that the survey could uncover the various differences in opinions. Open questions about what is needed to market BCIs in future did not result in many answers and were thus omitted in the final survey. Finally, more focus on the ethical part was ensured by eliminating many general questions about BCIs.

\section{The Asilomar Survey}

The final Asilomar survey consisted of 24 items (see Appendix I). The survey assessed 1) demographic information and opinions about 2) preferred terminology and definition of BCI, 3) marketability of different types of BCI applications, 4) ethical aspects related to BCI research, development and dissemination and 5) matters of urgency. One final open question asked respondents which questions should have been included in the survey that were not included. The survey was available through internet and on paper.

At the 4th International BCI conference at the Asilomar conference grounds, we encouraged participation in the survey through posters, two oral announcements at general lectures and one email. One week after the conference a follow-up email was send to all attendees of the conference to encourage final participation. The survey was closed 2 weeks after the conference. Throughout the paper the word "respondents" will refer to the BCI researchers who participated in the survey, while "participants" will refer to persons participating in BCI studies.

\section{Results}

Respondents' Profiles

A total of 289 persons are estimated to have attended the 4th International BCI conference. People were not asked not to share the survey internet link with other 
BCI scientists they might know, so there may have been more persons that learned about the existence of the survey. For convenience, we assume that 289 persons were asked to participate in the survey. One hundred and 66 persons responded to the request for participation (57.4\%). One hundred and 45 persons (50.2\%) completed the whole survey, although some items were left unanswered with the comment that respondents did not want to answer that question. Consequently, we will indicate how many respondents answered each item in the Results section. Respondents' details can be found in Table 1. One respondent preferred not to indicate his/her demographical data. Respondents consisted of 105 males and 39 females. Seventy three persons were aged between 18 and 30, 69 persons between 31 and 55, and two persons were aged between 56 and 70. The sample consisted of persons from various disciplines (see Fig. 1): neuro-, computer or cognitive scientists, electrical engineers, psychologists etc. The year in which respondents began with BCI research ranged from 1970 to 2010. Only 12 respondents started with BCI research before 2000 . However, this is difficult to avoid due to the youth of the BCI research field, with the substantial majority of publications in the last few years $[5,53]$. We will refer to this group as "experienced researchers". Thirty-nine respondents, whom we will refer to as "moderately experienced researchers", started with BCI research between 2000 and 2005. Another 92 persons, "new

Table 1 Overview of profiles of respondents

\begin{tabular}{llrr}
\hline Demographics & $\begin{array}{l}\text { Number } \\
\text { of answers }\end{array}$ & & Respondents \\
\hline What's your gender? & $N=144$ & Male & $72.9 \%$ \\
What's your age & $N=144$ & \multicolumn{1}{c}{ Female } & $27.1 \%$ \\
(years)? & & $18-30$ & $0 \%$ \\
& $31-55$ & $50.7 \%$ \\
& $56-70$ & $1.4 \%$ \\
In which year did & $N=143$ & before 2000 & $0.9 \%$ \\
you start with & & $2000-2005$ & $27.3 \%$ \\
BCI research? & & $2006-2010$ & $64.3 \%$ \\
Where do you live & $N=144$ & Asia & $7.6 \%$ \\
and perform this & & Europe & $41.7 \%$ \\
occupation? & & North-America & $50.7 \%$ \\
& & & \\
\hline
\end{tabular}

researchers" started between 2006 and 2010. About one third of the respondents were $\mathrm{PhD}$ students.

Eleven respondents worked as BCI researchers in Asia, 60 respondents in Europe and 73 respondents in North-America.

\section{Terminology and Definition of BCIs}

First, the survey assessed which name the respondents preferred for systems that "measure signals from the central nervous system and "translate" those signals into output signals". Notably, this phrasing refers only to devices that read from the CNS. Thus, we specifically asked respondents for an appropriate name for the systems we research and consider BCIs. Table 2 provides an overview of the responses. The majority of the respondents $(83.6 \%)$ preferred the phrase Brain-Computer Interface over Brain-Machine Interface, although some commented that "both terms are equally fine". Others commented that they would use BCI to refer to non-invasive systems and BMI to refer to invasive systems. Researchers from Asia and (moderately) experienced researchers seem to prefer the term BMI more often than the new researchers.

Furthermore, we assessed respondents' views on a current "hot" topic in the BCI community. BCIs can be distinguished based on the amount of "will" the user exerted to produce the signal in the EEG [69, 72]. BCIs which rely on the user to self-regulate certain brain patterns (e.g. mu rhythm or slow cortical potentials) are dubbed as spontaneous or active BCI. BCIs which rely on a evoked responses in a user's brain (e.g. P300 evoked potential) by presenting it external stimuli but asking a user to willfully attend to one of the stimuli are dubbed evoked or reactive BCIs. Finally, BCIs which rely on ongoing brain activity (e.g. arousal level) while the user is not willfully producing these signals or attending any special stimuli are dubbed passive BCIs. ${ }^{2}$ The BCI community has debated whether passive BCIs should be considered as BCIs as they do not seem to fit Wolpaw's definition from 2002 [69, 71]. In our sample $(N=143)$ all respondents agreed that active systems are BCIs. Almost all respondents (95.1\%)

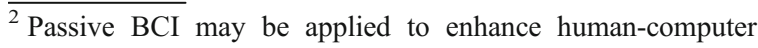
interaction. For example, when a user with disabilities is working with assistive technology, but the passive BCI detects sleep spindles in the brain pattern of the user, the system could switch to standby mode or dim the lights.
} 
Fig. 1 Overview of the professional and occupational activities of respondents. They were allowed to give several answers
What's your profession or occupation? (you can choose more than one)

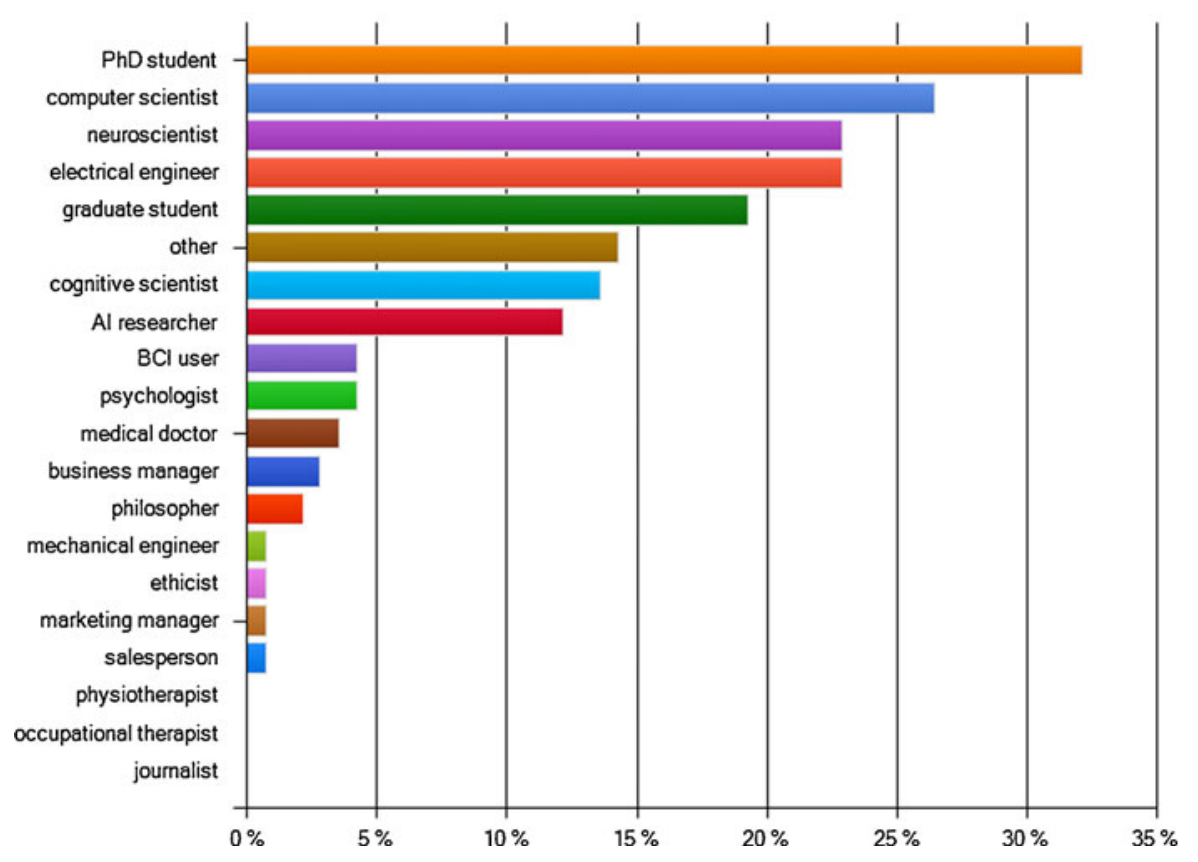

also consider reactive systems to be exemplary BCIs. Although respondents are less sure about passive systems, a majority (65.7\%) also view these as BCIs. Notably, passive systems seem more accepted as BCIs in Asia (81.8\%) and not well accepted as BCIs by experienced researchers $(41.7 \%)$.

Second, we asked respondents to evaluate several examples and indicate whether they did or did not consider the system a BCI. They could also indicate that they did not know. Some systems can be categorized as active, reactive and passive systems, but we did not mention these phrases. Figure 2 provides an overview of the answers. Respondents almost unanimously agreed that cursor control or orthosis control based on self-regulation of slow cortical potentials in the EEG or mu rhythm can be considered as BCI examples. Sixty-four percent considered fatigue monitor for drivers in a car that was based on brain signals a BCI, but a similar offline $^{3}$ system to assess alertness in workers was not considered to be a BCI by another $64 \%$ or the respondents. Similar to the fatigue monitor, the

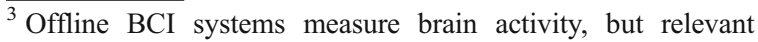
features are, unlike with online BCIs, not extracted and "translated" to commands in real time. Rather, relevant features in the signals are only extracted and classified after the experiment.
}

adaptation to the emotion of a user in a virtual game was considered a BCI by $65 \%$ of the respondents. Since a fatigue monitor and a emotion adapter are examples of passive BCIs, the results are compatible with the findings described in the previous paragraph.

Opinions were divided about a number of issues. Fifty-three percent of the respondents did not consider an EEG lie detector as a BCI, but $41 \%$ did. Forty-four percent of the respondents considered image detection (in other words whether a recently presented object stands out) as a BCI, although $37 \%$ did not. Nineteen percent of the respondents indicated that they did not know if they considered image detection as a BCI, which may reflect that the example was not sufficiently clear. We suspect that respondents felt they could decide whether this was a BCI or not because we did not specify whether image classification would take in realtime or near realtime. This factor has been indicated as particularly important for the definition of a BCI (see next paragraph). Respondents also did not agree whether a remote controlled rat was an example of a BCI. Forty-four percent thought so, and $38 \%$ did not think it is a BCI. Neuromarketing, which uses the classification of brain responses to advertisements or new products, also divides opinions. Finally, $61 \%$ of the respondents would not consider a retinal implant as a BCI example. These results 
Table 2 Overview of preferred name: BCI = Brain-Computer Interface; BMI = Brain-Machine Interface; BNCI $=$ Brain/neuronal Computer Interface and assessment of three different types of BCI. See Appendix I for the complete question

\begin{tabular}{|c|c|c|c|c|c|c|c|c|}
\hline \multicolumn{2}{|l|}{ Terminology and Definition } & \multirow{2}{*}{$\begin{array}{r}\text { All } \\
83.6\end{array}$} & \multirow{2}{*}{$\begin{array}{c}\text { Europe } \\
87.7\end{array}$} & \multirow{2}{*}{$\begin{array}{c}\text { North-America } \\
78.9\end{array}$} & \multirow{2}{*}{$\begin{array}{r}\text { Asia } \\
90.9\end{array}$} & \multirow{2}{*}{$\begin{array}{l}\begin{array}{l}\text { Experienced } \\
\text { experts }\end{array} \\
66.7\end{array}$} & \multirow{2}{*}{$\begin{array}{l}\begin{array}{l}\text { Moderately } \\
\text { experienced } \\
\text { experts }\end{array} \\
81.6\end{array}$} & \multirow{2}{*}{$\begin{array}{r}\begin{array}{l}\text { New } \\
\text { experts }\end{array} \\
86.4\end{array}$} \\
\hline Which name has your & $\mathrm{BCI}$ & & & & & & & \\
\hline & BMI & 12.9 & 10.5 & 15.5 & 9.1 & 25.0 & 18.4 & 9.1 \\
\hline & Direct Neural Interface & 3.6 & 1.8 & 5.6 & 0 & 8.3 & 0 & 4.5 \\
\hline & $\mathrm{BNCI}$ & 0 & 0 & 0 & 0 & 0 & 0 & 0 \\
\hline & Number of answers & 140 & 57 & 71 & 11 & 12 & 39 & 88 \\
\hline \multirow{4}{*}{$\begin{array}{l}\text { In your opinion, which of } \\
\text { these devices is a BCI? } \\
\text { (you may choose more } \\
\text { than one) }\end{array}$} & Evoked/reactive & 95.1 & 98.3 & 95.8 & 81.8 & 91.7 & 97.4 & 95.6 \\
\hline & Spontaneous/active & 100 & 100 & 100 & 100 & 100 & 100 & 100 \\
\hline & Emotive/passive & 65.7 & 60.0 & 67.6 & 81.8 & 41.7 & 76.9 & 64.4 \\
\hline & Number of answers & 143 & 60 & 71 & 11 & 12 & 39 & 90 \\
\hline
\end{tabular}

demonstrate that $\mathrm{BCI}$ researchers often do not agree on what is and what is not a BCI.

Thirdly, we asked the respondents which of 6 elements (see Appendix I, item 11) is required for a definition of a BCI, but respondents could also add more elements in the comments. Half or more than half of the respondents identified 4 elements as crucial (in order of importance); a BCI:

1) must detect brain activity directly (without using signals from peripheral nerves or muscles) (83.8\% of the respondents).
2) provides feedback in realtime, or neartime ( $71.1 \%$ of the respondents).

3 ) must classify brain activity (60.6\% of the respondents).

4) provides feedback to the user that reflects whether s/he successfully attained a goal $(50.0 \%$ of the respondents).

Only $20 \%$ of the respondents believed that it is required that the user chooses to send a signal each time. In other words, the device can also rely on signals that the user produces involuntarily as with
Fig. 2 The percentage of people who did (orange) or did not (blue) consider the listed example as a BCI or who did not know (purple bar)

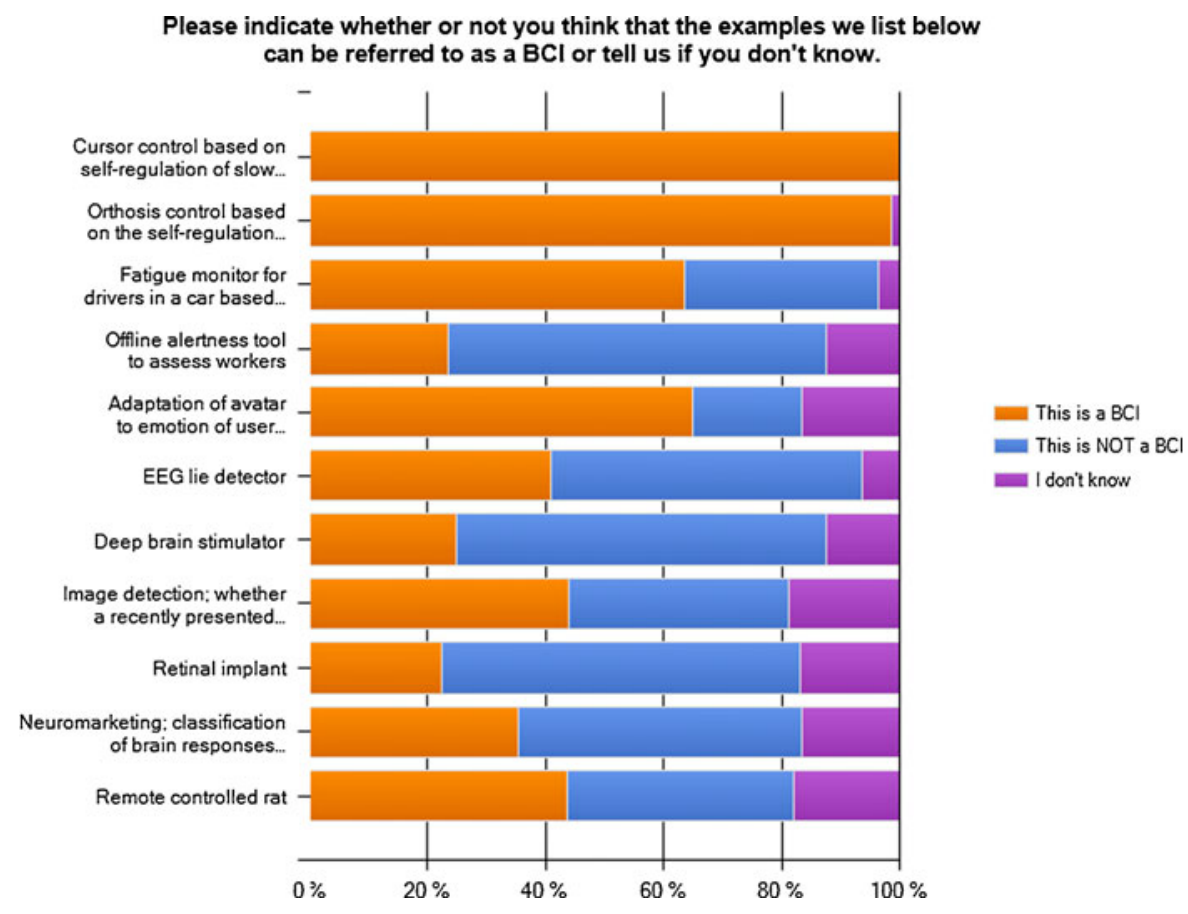


passive BCIs. Similarly, only $9 \%$ of the respondents believe a BCI is only a BCI when it is used solely for the purpose of sending a message or command.

Comments from respondents reflected mainly the question if 'feedback' is important. For example, one respondent defines $\mathrm{BCI}$ as a "realtime or neartime communication channel directly from the central nervous system to a computer [and that] this communication may be 'active' or 'passive', but need not provide feedback to the user". Another respondent was of a different opinion: "If a BCI does not provide feedback there is no 'interface' and the device or system is simply a monitor. One could also argue that user can receive feedback because they sense human-computer interaction alters in concordance with their state" Finally, only 1 respondent remarked that "the communication can go in the direction from the computer into the brain such as with electrical stimulation to alter the state of the brain". If we would draw the conclusion from this that a general trend is to emphasize feedback as an essential aspect of BCI, then this is somewhat inconsistent with the results from Fig. 2 that show what applications are and are not considered to be an example of BCI. As many as $43.8 \%$ of the respondents consider a remote controlled rat as an example of BCI, yet retinal implants are not considered a BCI. Also, $24.8 \%$ of the respondents consider Deep Brain Stimulation a Brain-Computer Interface.

Thus, it is clear that "BCI" researchers differ significantly amongst themselves about the definition of Brain-Computer Interfaces. More clarity concerning the interpretation of what a $\mathrm{BCI}$ is (or is not) is important, especially in discussions with philosophers, policy makers, health care organizations, ethicists and the general public. However, we do not want to attempt to provide a standard definition here. Any such definition should ideally be developed through consensus amongst many established researchers, but it is more likely the definition will evolve naturally over time.

At least, we would like to stress the current variety in definitions, and the ensuing risk of misinterpretation. Groups who address ethical or other issues in BCI research should clarify their interpretations of the term "BCI" and how this might influence the specific nuances of their (ethical) position.

Expected Marketability of BCIs

As discussed in the introduction, the expected marketability of future BCI products influences the timing and the pace of the ethical debate. However, a myriad of future BCIs can be imagined. In the survey, for convenience, we have ordered some BCI types based on their function:

1. BCIs for healthy users

2. BCIs as assistive technology, which provides compensation for loss of motor function (e.g. BCI-controlled communication program or wheelchair)

3. BCI-controlled prostheses, which restore motor function by replacing a paralyzed limb by a prosthesis (e.g. a BCI-controlled robotic arm or leg)

4. BCIs as therapy tools, which help people with psychological/neurological disorders to directly use feedback of their brain activity for training/ recovery purposes (e.g. neurofeedback of sensorimotor rhythms may promote brain recovery after stroke, neurofeedback of slow cortical potentials may help improve attention).

Although a state-of-the-art technology assessment would have to specify applications in more detail (for example the invasiveness of the $\mathrm{BCI}$ ), these questions at least add some sense of the opinions of $\mathrm{BCI}$ researchers on marketability. For each of these types of BCIs, we asked respondents to indicate when they expected such a BCI to become available on the market. Options were 1) never, 2) between 0 and 5 years, 3) between 6 and 10 years, 4) more than 10 years, and 5) it already exists on the market. If respondents believed such a BCI was already on the market, then they were asked to comment which group or company offers it. Figure 3 provides an overview of the respondents' answers.

First, $44.8 \%$ of the respondents $(N=145)$ expect BCIs for healthy people to become available on the market within the next 5 years, $13.8 \%$ between 6 and 10 years and $12.4 \%$ in more than 10 years. Few people $(1.4 \%)$ believe it will never become 

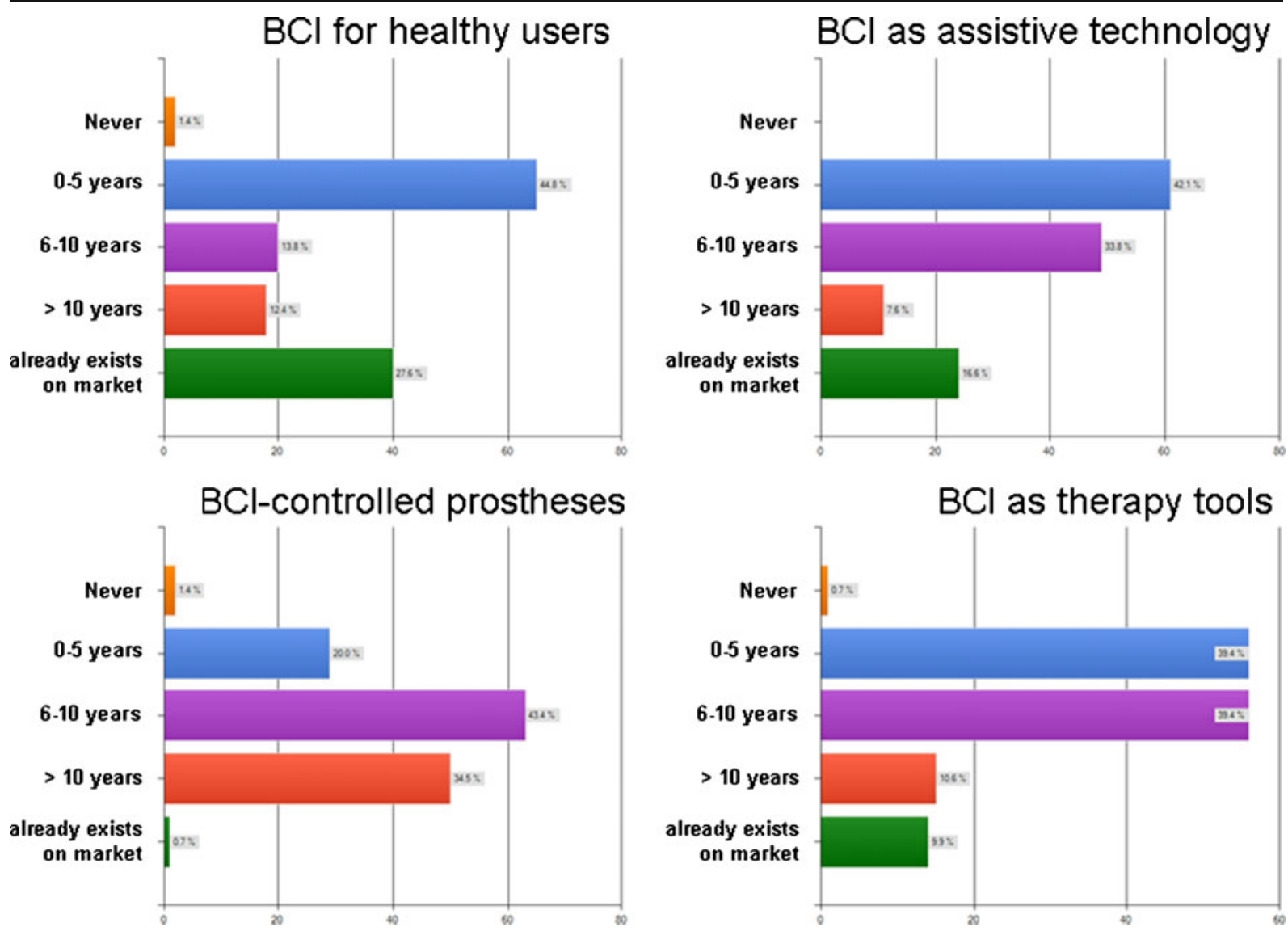

Fig. 3 These figures show how respondents (in percentages) estimated the time needed for a BCI to reach the market

available on the market and $27.6 \%$ of the respondents believe it is already on the market. The companies mentioned are Neurosky, Emotiv, InterAxon, Mattel, Brain Actuated Technologies, ZEO, OCZ, Uncle Milton, NIA, Ambien Audeo, and Hitachi. Some respondents add a critical note, for example: "if it [the products these companies are selling] is really BCI and not EMG+EEG". Another respondent however specifies: “.... what NeuroSky, Emotiv, etc. are doing is BCI. But it's crude and not what we all dreamed of seeing (the "EEG-headsetcontrols-computer-in-many-dimensions" thing) when we got into this field. That's at least 10 years off".

Second, every respondent $(N=145)$ believed that BCIs as assistive technology will become available on the market. Most respondents $(42.1 \%$ of $N=145)$ expect a BCI as assistive technology to become available on the market within the next 5 years,
$33.8 \%$ between 6 and 10 years and $7.6 \%$ in more than 10 years. Almost $17 \%$ of the respondents think BCI as AT is already on the market and mention predominantly g.tec, which sells the Intendix Home BCI System, as well as software like OpenVibe and BCI2000.

Third, most respondents $(43.4 \%, N=145)$ believe BCIs as prostheses will become available on the market between 5 and 10 years. Another large group (34.5\%) believes it will take more than 10 years. One respondent commented: "It was clear during the conference that if other muscles/nerves are available, no company will think to produce [BCI-controlled] prosthesis for amputated users. If here BCI-controlled prostheses is intended also for SCI users, I believe that in more than 10 years it could be available on the market". The first probably refers to the keynote lecture from Dr. Zev Rymer at the 4th International 
BCI conference in Asilomar, which stated that as long as prostheses or assistive technology can be controlled with remnant muscles or nerve activity, and as long as the longevity of the neuronal recordings of the central nervous system remains limited, there will be no need, let alone a market, for BCI technology. However, an opposing view argues that BCIs can be valuable to persons with limited motor function, such as when these channels are unavailable due to fatigue [30, 37, 47].

Twenty percent of the respondents believe prostheses will be on the market within the next 5 years. Two persons $(1.4 \%)$ do not think BCI-controlled prosthesis will ever reach the market and 1 person $(0.7 \%)$ thinks such products are already on the market stating that: "The Parastep-1 system may have been the first, depending on how strictly you define BCF".

Fifth, a large group of respondents (39.4\%) think BCIs as therapy tools will become available on the market within the next 5 years. An equally sized group believes this will happen between 6 and 10 years. One person believes BCIs will never be on the market as therapy tools, but unfortunately did not comment on her choice. Additionally, 9.9\% of the respondents say BCI technologies are already on the market as therapy tools. Some examples of companies are EEGInfo and Brainmaster. However, some persons comment that "On the market doesn't mean it is proven to work" illustrating the scepticism of many BCI researchers towards neurofeedback therapy. Finally, one respondent commented: "Folks who do $D B S$ are working on plenty of interesting ways to adaptively program DBS based on user and brainsignal feedback. That counts as BCI in my book" illustrating again that the definition of a BCI is critical in any discussion of ethical or other issues.

To conclude, respondents had different views on the marketability of different BCI systems. This creates some challenges for ethical discussions, because it is difficult to determine which issues are most urgent without agreement on which BCIs are most imminent.

Ethical Issues Related to BCIs as Assistive Technology

\section{Informed Consent}

Before asking respondents to rate their agreement with statements about the informed consent pro- cess, we explained that informed consent is the process in which participants or legal representatives of participants are fully informed about the study the participant is entering and legally agree to participation.

We included six items related to informed consent, since it is an urgent practical issue in BCI research $[22,61]$. We first review the statements that focus on the most vulnerable patients who are in the complete locked-in state (CLIS). CLIS patients cannot communicate in any way, whereas locked-in patients (LIS) usually have minimal residual muscle movement with which they can signal yes/no responses to questions caregivers, legal representatives or researchers might ask [27, 29]. The informed consent process with LIS patients takes effort and time, but can be straightforward. Haselager and colleagues suggested some guidelines researchers could follow when engaging with a legal representative and LIS patient in this process [22]. However, it is unclear how the BCI researchers should act when, as has been experienced, family members of CLIS patients ask BCI laboratories for an intervention.

Table 3 provides an overview of the answers of the respondents. Most respondents (75.7\%) mostly or completely disagree that a person who cannot communicate cannot be included in BCI studies even when their legal representative agrees with participation. When we phrased this differently, most respondents $(74.1 \%)$ mostly or completely agreed that patients who cannot communicate can be included in BCI studies when the legal representative asks for a BCI intervention. However, some respondents commented that inclusion of complete locked-in patients who cannot communicate in BCI studies depends on whether or not the BCI would use non-invasive or invasive recording. Respondents argued that CLIS patients should not be included in invasive studies or suggested that patients could set up a living will that specifies under "which constraints a BCI experiment may take place". The urgency of this last suggestion is illustrated by the fact that most patients do not have living wills or do not have precisely formulated living wills even for lifetreatments (e.g. tracheotomy) [36].

Consequently, $67 \%$ of the respondents mostly or completely disagreed that one should still attempt to provide a BCI to a non-communicative patient when the legal representative does not agree. 
Table 3 Overview of statements regarding the informed consent process. Columns 2 to 5 show the percentage of respondents (dis)agreeing (with the extent indicated in the column) to the different statements The last column (response count) indicates how many respondents scored the statement

\begin{tabular}{|c|c|c|c|c|c|c|}
\hline Statement & $\begin{array}{l}\text { Disagree } \\
\text { completely }\end{array}$ & $\begin{array}{l}\text { Mostly } \\
\text { disagree }\end{array}$ & I don't know & Mostly agree & $\begin{array}{l}\text { Agree } \\
\text { completely }\end{array}$ & $\begin{array}{l}\text { Response } \\
\text { count }\end{array}$ \\
\hline $\begin{array}{l}\text { People who cannot communicate in any way should } \\
\text { *not* be included in BCI studies even if their legal } \\
\text { representative agrees with their participation }\end{array}$ & 33.3 & 42.4 & 12.5 & 9.7 & 2.1 & 144 \\
\hline $\begin{array}{l}\text { Obtaining an informed consent from a locked-in patient } \\
\text { should be video-taped }\end{array}$ & 4.2 & 9.0 & 31.9 & 34.7 & 20.1 & 144 \\
\hline $\begin{array}{l}\text { A BCI expert is the suited person to inform the } \\
\text { locked-in patients about the BCI studies, the risks } \\
\text { and the benefits }\end{array}$ & 4.9 & 18.8 & 13.2 & 49.3 & 13.9 & 144 \\
\hline $\begin{array}{l}\text { A medical expert is the suited person to inform the } \\
\text { locked-in patients about the BCI studies, the risks and } \\
\text { the benefits }\end{array}$ & 2.1 & 17.6 & 14.8 & 59.2 & 6.3 & 142 \\
\hline $\begin{array}{l}\text { If a patient has no means to communicate but the legal } \\
\text { representative of a patient asks for a BCI intervention } \\
\text { then an attempt should be made to provide him or her } \\
\text { with a BCI }\end{array}$ & 0 & 8.4 & 17.5 & 53.8 & 20.3 & 143 \\
\hline $\begin{array}{l}\text { If a patient has no means to communicate, and the legal } \\
\text { representative does not agree to a BCI intervention, } \\
\text { you should still attempt to provide a BCI }\end{array}$ & 37.8 & 29.4 & 21 & 8.4 & 3.5 & 143 \\
\hline
\end{tabular}

Twenty-one percent indicated not knowing the answer, but some commented again that it depended on the invasiveness of the recording. Seventeen persons (11.9\%) mostly or completely agreed a BCI intervention should be attempted even if the legal representative does not agree. Three people commented on their choice. The first person asked: "what if the person has clearly expressed his/her thoughts about "extreme" treatments (before getting into a LIS)?" The second and third person only agreed to this option when the BCI procedure was non-invasive. One of the five persons who completely agreed in our survey commented (in personal communication with one of the authors) that it would be unethical not to attempt to help this people.

Thus, the BCI community seems to have a general consensus that CLIS (non-communicative) patients can be included in non-invasive BCI research when the legal representatives agree. However, the BCI community seems to generally agree that CLIS patients should not be included in invasive BCI research or when the legal representative does not agree. Although in theory legislation exists about how and when to include legally incompetent persons in scientific studies, the opinion of the researchers does influence the legal representative. The legal representative, who may be faced with a non-communicative patient, may not have the background needed to scrutinize the information given by the research team. If the research team presents the study plan too optimistically the legal representative may not realize this.

Researchers did not agree on videotaping the process of obtaining an informed consent in a case with a LIS patient. Fifty-five percent of the respondents mostly or completely agreed that the process should be video-taped, but $32 \%$ did not know.

Finally, we focused on the question of which person(s) should inform LIS patients about BCI studies, the risks and the benefits. Sixty-three percent of the respondents mostly or completely agreed that the BCI expert is appropriate, but $66 \%$ of the respondents also agreed that a medical doctor is appropriate. Twelve persons commented that these persons should work together or at least that knowledge from both or more disciplines is necessary. The presence of a medical doctor in the informed consent process is even more desired by some respondents when invasive BCI methods are used. One person expressed concern that $\mathrm{BCI}$ researchers may be 
biased, another that computer scientists are not necessarily equipped or sufficiently experienced to have such conversations. Finally, one person may have expressed the general concern well: "I do not believe that a single party can, in all situations, adequately inform the patient about all issues concerning a BCI study. In such cases, I believe it would be more appropriate for experts with complementary areas of expertise .... to inform the patient. This raises the issue of whether multiple perspectives are consistent. It is not clear to me how this can be resolved systematically".

We could cautiously conclude that the BCI community acknowledges the role of the BCI expert and the medical doctor in the process of obtaining informed consent, but that a broader debate is needed on this topic. Haselager et al. (2009) point out that, in relation to team responsibility and patient communication, much can be learned from interdisciplinary teams such as intensive care units (ICU), teams concerned with patients who have severe mental disorders [31], or chronic or progressively ill patients facing end-oflife care decisions. Thus, we suggest that we could learn from similar cases in the medical system (e.g. in relation to surgery with very elderly people). The BCI community might benefit from a state-of-theart overview of medical decision making procedures. We suggest that, at future BCI workshops and conferences, the organizers could invite experts on medical decision making to inform the audience and contribute to the debate. Another practical recommendation could be to assess perspectives on BCI, risks and benefit in different disciplines and establish (and evaluate) an overall consistent position. Without consistency we might have to conclude that obtaining informed consent will always be a custom-tailored process to each individual, but (some) consistency could facilitate tentative guidelines avoiding unacceptably large 'local variations' (see for further recommendation the section on "team responsibility").

\section{Benefits and Risks}

A thorough analysis of risks and benefits is essential for both medical decisions and ethical evaluations.
However, the scientific community has not yet established a reasonable expectancy of the possible benefit of a BCI. Moreover, for people who are (on the verge of being) locked-in, the potential benefit of a BCI, lacking alternatives, means the difference between communicating and not communicating at all [22]. Here, we asked respondents to rate several statements about risks and benefits of non-invasive versus invasive BCIs as assistive technology for locked-in patients (see Table 4).

Most BCI researchers (87.5\%) indicated that they mostly or completely agreed that the current benefits outweigh the current risks of non-invasive BCI for locked-in patients. A somewhat smaller majority $(70.7 \%)$ indicated that they mostly or completely disagree that the risks of non-invasive BCI are largely unknown.

BCI researchers had different views about the riskbenefit analysis concerning invasive BCIs. Thirtythree percent of the respondents did not know whether the current benefits of invasive BCI outweighs the current risks. This outcome corresponds with the result that more than half of the respondents mostly or completely agreed that the risks of invasive BCIs are argely unknown. One respondent commented: "Invasive BCIs are certainly useful. Risks are likely low, but this is still not proven at this point". Another respondent has a different opinion: "I think the risks of invasive BCI are fairly wellknown, actually. Just not sure the current benefits are enough. As soon as someone comes out with a good ECoG-based BCI system I would say the benefits outweigh the risks, and I wouldn't think twice about signing up for an implant myself if I was locked-in". Another two respondents pointed out that the riskbenefit analysis should be done on a patient-bypatient basis and cannot be generalized to all patients.

Thus, although there seems to be more agreement on the risk-benefit analysis of non-invasive BCIs compared to invasive $\mathrm{BCIs}$, respondents do agree that empirical data is needed and risk-benefits analysis can only be done individually.

Like in every other medical intervention it is essential to distinguish between effectiveness of the intervention and the patient's benefit. While physicians and researchers can judge whether a 
Table 4 Overview of statements regarding the risks and benefits. Columns 2 to 5 show the percentage of respondents (dis)agreeing (with the extent indicated in the column) to the

\begin{tabular}{|c|c|c|c|c|c|c|}
\hline Statement & $\begin{array}{l}\text { Disagree } \\
\text { completely }\end{array}$ & $\begin{array}{l}\text { Mostly } \\
\text { disagree }\end{array}$ & $\begin{array}{l}\text { I don't } \\
\text { know }\end{array}$ & $\begin{array}{l}\text { Mostly } \\
\text { agree }\end{array}$ & $\begin{array}{l}\text { Agree } \\
\text { completely }\end{array}$ & $\begin{array}{l}\text { Response } \\
\text { count }\end{array}$ \\
\hline $\begin{array}{l}\text { The current benefits outweigh the current risks of } \\
\text { non-invasive BCI for locked-in patients }\end{array}$ & 1.4 & 3.5 & 7.7 & 41.3 & 46.2 & 143 \\
\hline The risks of non-invasive BCIs are still largely unknown & 22.4 & 48.3 & 11.2 & 16.1 & 2.1 & 143 \\
\hline $\begin{array}{l}\text { The current benefits outweigh the currently risks of } \\
\text { invasive BCI for locked-in patients }\end{array}$ & 11.3 & 29.6 & 33.1 & 23.2 & 2.8 & 142 \\
\hline The risks of invasive BCIs are still largely unknown & 0.7 & 24.8 & 17.7 & 46.8 & 9.9 & 141 \\
\hline
\end{tabular}

different statements The last column (response count) indicates how many respondents scored the statement
BCI is effective, pure effectiveness dose not entail a normative justification. Normatively relevant is the benefit for the patient. While effectiveness is usually a necessary prerequisite, it also depends on patient's individual preferences $[10,60]$. We recommend monitoring each patient's benefits through open, in-depth interviews following BCI use.

\section{Team Responsibility}

Previous and current BCI studies that include severely paralyzed or locked-in patients involve a large team of researchers from various disciplines. Team members typically visit patients 1 or 2 times per week at home to do experiments [23, 25, 26, 38, 39, 64] and sometimes patients are involved in studies over years [6, 41, 55, 57, 64]. Inevitably, patients interact with many researchers, and conversations about BCIs, risks and benefits might differ from researcher to researcher. Since researchers may have different backgrounds or expectations, as well as different views about key issues, the responsibility for the effects of BCIs can become unclear due to team work [22]. Here, we asked respondents to rate several statements about team responsibility (see Table 5).

A majority of the respondents (73\%) mostly or completely agree that all BCI teams should have 1 common code with rules and regulations for team responsibility issues. Respondents also differed on whether patients can or cannot hear different opinions from team members. While $41 \%$ of the respondents agree that it is okay that a patient hears the difference of opinion of various team members considering the risks and the benefits of a BCI, $60 \%$ of the respondents agree (when formulated differently) that BCI teams should stick to one risk/benefit analysis. One respondent wrote: "It's very important to have one clear message. The last thing we want is the patient to become confused", while another wrote: "The ability for users and/or patients to obtain a second opinion is extremely important. This is widely accepted in other medical professions as well".

To conclude, BCI researchers seem to disagree about whether and how BCI teams should operate and give information as a unit. BCI teams could learn from other interdisciplinary groups working in similarly demanding situations such as intensive care units [31]. Haselager and colleagues recommend several strategies to improve team functioning, many of which are reasonably obvious (e.g. regular team meetings, ensuring good lines of communication), but two recommendations are worth mentioning in relation to acquiring informed consent [22]. First, ensure that appropriate members of the team are asked whether they should be present at a decision making meetings with patient and family. Second, have a 'preconference' of team members to develop team consensus and facilitate discussion of issues or conflicts that may occur within a team [56].

Consequences of BCI on Patients' and Familes' Lives

Most BCI researchers who aim to develop BrainComputer Interfaces assume that AT will increase quality of life for persons with disabilities and their families. Increased quality of life, or assurance that communication will remain intact, could very well 
Table 5 Overview of statements regarding team responsibility. Columns 2 to 5 show the percentage of respondents (dis) agreeing (with the extent indicated in the column) to the

\begin{tabular}{|c|c|c|c|c|c|c|}
\hline Statement & $\begin{array}{l}\text { Disagree } \\
\text { completely }\end{array}$ & $\begin{array}{l}\text { Mostly } \\
\text { disagree }\end{array}$ & $\begin{array}{l}\text { I don't } \\
\text { know }\end{array}$ & $\begin{array}{l}\text { Mostly } \\
\text { agree }\end{array}$ & $\begin{array}{l}\text { Agree } \\
\text { completely }\end{array}$ & $\begin{array}{l}\text { Response } \\
\text { count }\end{array}$ \\
\hline $\begin{array}{l}\text { All BCI teams should have } 1 \text { common code with rules } \\
\& \text { regulations for team responsibility issues }\end{array}$ & 0.7 & 14.8 & 12 & 45.1 & 27.5 & 142 \\
\hline $\begin{array}{l}\text { It is okay when a patient hears about the difference op } \\
\text { opinion of various team members considering the } \\
\text { risks and the benefits of a BCI }\end{array}$ & 12.7 & 31 & 15.5 & 29.6 & 11.3 & 142 \\
\hline $\begin{array}{l}\text { BCI teams should stick to one risk/benefit analysis } \\
\text { and tell this to the patient }\end{array}$ & 4.2 & 14.1 & 21.8 & 43.0 & 16.9 & 142 \\
\hline
\end{tabular}

different statements The last column (response count) indicates how many respondents scored the statement change end-of-life decisions among persons with neurodegenerative diseases. One article proposed that AT, especially AT that requires a difficult and timeconsuming set-up such as current BCI technology, could add to the burden of the family or caregivers and not aid them [48].

Sixty-four percent of the respondents thought that $\mathrm{BCI}$ as AT will be a reason for a patient to change his or her end-of-life decisions, but almost 30\% did not know whether this was true (See Table 6). Additional concern was expressed by one respondent: "Ultimately, I think that BCI technology will change end-of-life plans for some people. However, it is very important that users do not change their endof-life plans based on false hopes of obtaining technology that does not yet exist or is not yet widely available".

Forty-seven percent of the respondents mostly or completely disagreed that BCI will add an extra burden to the family of the patient. Those who did believe that BCI could, to some extent, add extra burden to the family said for example: “...while a potentially extended lifetime might add to burden, family members' perception might be of decreased burden or intangible gain. This will vary on a caseby-case basis and will be largely subjective for both patient and family member". More than $80 \%$ of the respondents did feel that BCI could also aid families. The common conclusion might be that BCIs may bring extra burden but also extra aid. One respondent said: "it definitely adds a burden, but it also lightens a load".

However, ultimately these issues demand empirical investigation. As one respondent stated: "These are empirical matters, which can only be evaluated by interrogating the relevant individuals and tracking such things as their continued financial solvency or the quality of filial relations over time". Additionally, again the BCI community might benefit from an investigation of how the medical practice or companies study the effects of new treatments and therapies.

Table 6 Columns 2 to 5 show the percentage of respondents (dis)agreeing (with the extent indicated in the column) to the different statements The last column (response count) indicates how many respondents scored the statement

\begin{tabular}{|c|c|c|c|c|c|c|}
\hline Statement & $\begin{array}{l}\text { Disagree } \\
\text { completely }\end{array}$ & $\begin{array}{l}\text { Mostly } \\
\text { disagree }\end{array}$ & $\begin{array}{l}\text { I don't } \\
\text { know }\end{array}$ & $\begin{array}{l}\text { Mostly } \\
\text { agree }\end{array}$ & $\begin{array}{l}\text { Agree } \\
\text { completely }\end{array}$ & $\begin{array}{l}\text { Response } \\
\text { count }\end{array}$ \\
\hline $\begin{array}{l}\text { A BCI as assistive technology will be a reason for a } \\
\text { patient to change his or her end-of-life decisions }\end{array}$ & 1.4 & 4.9 & 29.4 & 53.8 & 10.5 & 143 \\
\hline $\begin{array}{l}\text { BCI as assistive technology will add an extra burden } \\
\text { to the family of the patient }\end{array}$ & 9.2 & 38.0 & 33.8 & 19.0 & 0.0 & 142 \\
\hline BCI as assistive technology will aid the family of the patient & 0.0 & 1.4 & 16.8 & 72.0 & 9.8 & 143 \\
\hline
\end{tabular}




\section{Liability and Personal Identity}

The use of BCI may affect psychological aspects of a person, including his or her self-perception, types of behavior characteristic of a person, the capacity to remember, understand and decide upon information etc., possibly leading to questions about the psychological continuity or even personal identity of the person [2, 53, 54, 63]. Since these capacities are relevant to the process of informed consent (e.g. affecting someone's evaluation of a decision to continue or stop the use of a BCI) this is not 'just' an ethical issue but may also have legal implications (see [24] for a discussion of this topic in relation to Deep Brain Stimulation).

Also, BCI use could lead to accidents. For example, who is liable if a BCI mistakenly interprets a wheelchair or prosthesis command and causes a user to hit someone or damage something or cross a street against a red light $[8,61,63]$ ?

Sixty-five percent of the respondents mostly or completely agree that BCI users are responsible for the actions they execute and the messages they transmit with this device (See Table 7), although many respondents $(21.5 \%)$ don't know and commented that it would depend on many factors such as 1) the accuracy with which the BCI can decode the user's intentions, 2) the knowledge of the user about the unreliability of the system, 3) state of functionality at the time of an accident or 'adverse' event, 4) the competence of the user, and 5) the psychological health or state of the user at the time of the accident or 'adverse' event. Respondents are also unsure (37.1\%) whether BCIs as assistive technology would lead to behaviors uncharacteristic of the user's identity and comment that even if it would change personal identity, this might not be necessarily negative. For example, neurofeedback has been hypothesized to reduce the symptoms of autism and anti-personality disorder [49, 59] and may change a person's identity in fundamental but desirable ways.

Also, few comments demonstrate that some BCI researchers are worried that ethical guidelines will superimpose a particular moral perspective on patients: "perhaps a BCI user's "identity" would change once they had used the system for a while. But it would be beyond arrogant to tell them 'I think this might change your identity, so I am not allowing you to use this technology". In addition to this very basic ethical question, the possibility of BCI induced changes in cognitive capacities, psychological continuity or personal identity needs to be considered to assess issues concerning informed consent and/or personal liability.

Finally, respondents again commented that these issues should be investigated empirically, with the explicit consideration of the many factors influencing BCI use and likely outcomes. We agree and thus recommend that future clinical trials involving BCI systems investigate personality changes over time.

\section{Interaction with the Media}

BCI research, whether non-invasive or invasive, receives a great deal of media attention (e.g. [1, 11, $21,46,65])$. The media in turn is read by policy makers and stakeholders and may influence their opinions and expectancies, which, in turn, might

Table 7 Columns 2 to 5 show the percentage of respondents (dis)agreeing (with the extent indicated in the column) to the different statements. The last column (response count) indicates how many respondents scored the statement

\begin{tabular}{|c|c|c|c|c|c|c|}
\hline Statement & $\begin{array}{l}\text { Disagree } \\
\text { completely }\end{array}$ & $\begin{array}{l}\text { Mostly } \\
\text { disagree }\end{array}$ & $\begin{array}{l}\text { I don't } \\
\text { know }\end{array}$ & $\begin{array}{l}\text { Mostly } \\
\text { agree }\end{array}$ & $\begin{array}{l}\text { Agree } \\
\text { completely }\end{array}$ & $\begin{array}{l}\text { Response } \\
\text { count }\end{array}$ \\
\hline $\begin{array}{l}\text { BCI users are responsible for the actions they execute } \\
\text { and the messages they transmit with the device }\end{array}$ & 1.4 & 11.8 & 21.5 & 57.6 & 7.6 & 144 \\
\hline $\begin{array}{l}\text { BCIs as assistive technology could lead to behaviors } \\
\text { uncharacteristic of the user's personal identity }\end{array}$ & 5.6 & 27.3 & 37.1 & 28.0 & 2.1 & 143 \\
\hline BCIs as assistive technology will not change a person's identity & 0.7 & 11.9 & 33.6 & 42.0 & 11.9 & 143 \\
\hline
\end{tabular}


affect the availability of funding for BCI research. Here we asked BCI researchers how BCI researchers should disseminate results to the media.

Over $80 \%$ of the respondents agreed that BCI scientists have a responsibility to check whether journalists accurately separate factual from fictitious statements (See Table 8). However, as one respondent commented: "We can try our best to get correct info out there and ask to review anything a reporter writes before it goes to press, but sometimes it is simply out of our control". A similar majority agreed that BCI scientists should actively speak out against inaccurate media statements and should moderate enthusiasm when speaking to the media. Respondents did not agree on whether BCI scientists should restrict themselves to discussing only current or near-future applications of BCI. One respondent commented: "Scientists have the duty to tell facts. But that doesn't mean they cannot be enthusiastic about their field and have a vision".

Thus, there seems to be a consensus among BCI scientists to moderate enthusiasm when speaking to the media and to actively check and correct representations in the media whenever needed and/ or possible. However, BCI scientists disagree on whether they should restrict themselves in speaking about what is currently possible, or may speak about their expectations for future BCIs. Schermer points out that future brain-machine interaction technologies may entail political and ideological functions, since they help to secure research funds and to create a certain image of these developments, thus steering the public opinion [54]. We do recommend that scientists realistically portray their findings to the media and to academic journals. BCI developers should also thoroughly and accurately report methods in scientific papers, such as stating whether they include time between selections of targets in the calculation of the communication rate $[4,35,62]$. Another good practice for industrial BCI developers would be to realistically describe how much of the product relies on brain signal and how much on muscle signals.

\section{Urgent Matters in the BCI Community}

Finally, we asked respondents to indicate when certain BCI issues need to be settled. Figure 4 gives an overview. We will discuss these issues in order from most urgent to least urgent issues that need to be settled within the next 2 years.

First, $79 \%$ of the respondents $(N=143)$ indicated a standard BCI definition should be clarified within 5 years. However, those who disagreed often had strong opinions, with one respondent commenting: "I don't see a real reason to have a stand alone definition.... for BCI. Science these days is very interdisciplinary and trying to define borders is somewhat artificial (and not necessarily beneficial)". Another respondent commented: "not to be incendiary,

Table 8 Columns 2 to 5 show the percentage of respondents (dis)agreeing (with the extent indicated in the column) to the different statements The last column (response count) indicates how many respondents scored the statement

\begin{tabular}{|c|c|c|c|c|c|c|}
\hline Statement & $\begin{array}{l}\text { Disagree } \\
\text { completely }\end{array}$ & $\begin{array}{l}\text { Mostly } \\
\text { disagree }\end{array}$ & $\begin{array}{l}\text { I don't } \\
\text { know }\end{array}$ & $\begin{array}{l}\text { Mostly } \\
\text { agree }\end{array}$ & $\begin{array}{l}\text { Agree } \\
\text { completely }\end{array}$ & $\begin{array}{l}\text { Response } \\
\text { count }\end{array}$ \\
\hline $\begin{array}{l}\text { It is the responsibility of scientists to check whether } \\
\text { their separation from the facts and fiction is } \\
\text { adequately represented by journalists }\end{array}$ & 2.1 & 9.1 & 7.7 & 51.0 & 30.1 & 143 \\
\hline $\begin{array}{l}\text { BCI scientists should moderate their enthusiasm } \\
\text { when speaking to the media }\end{array}$ & 1.4 & 12.6 & 9.8 & 37.8 & 38.5 & 143 \\
\hline $\begin{array}{l}\text { Each BCI scientist should restrict him/herself to } \\
\text { discussing current and near-future applications of } \\
\text { BCI instead of speculating about long-term } \\
\text { applications }\end{array}$ & 3.5 & 31.9 & 9.7 & 36.8 & 18.1 & 144 \\
\hline $\begin{array}{l}\text { BCI scientists should actively speak out against } \\
\text { inaccurate statements in the media, regardless } \\
\text { of the source }\end{array}$ & 0.0 & 4.2 & 9.0 & 47.2 & 39.6 & 144 \\
\hline
\end{tabular}


Fig. 4 An overview of when respondents think certain BCI issues should be settled. From top to bottom bar: 'a certification process to determine that the product is adequate for a BCI', 'a regular journal devoted solely to BCI research', 'a certification process to determine that a $\mathrm{BCI}$ scientist is qualified to work with patients', 'ethical guidelines specific to BCI research and BCI use' and 'a standard definition of what a BCI is'
Please indicate in what period the items listed belowed need to be settled.

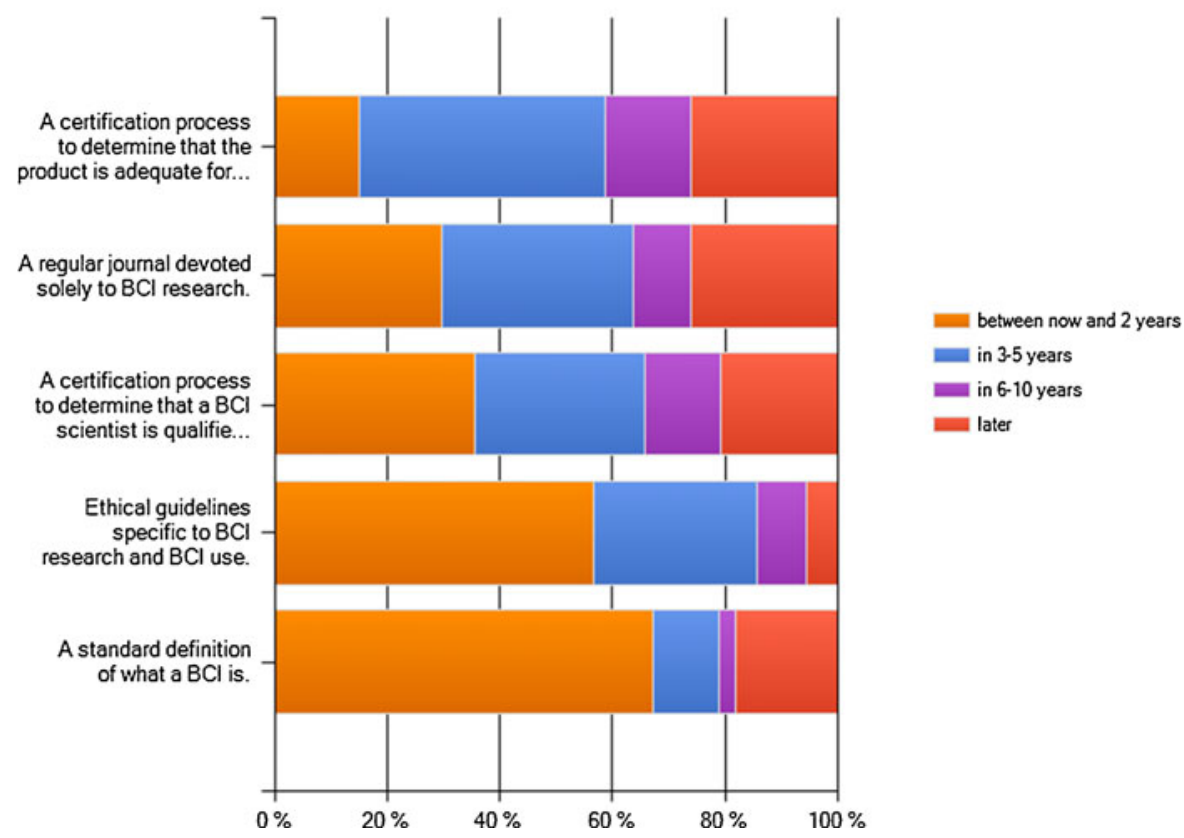

but who cares, really?" Another example is: "it seems kind of ridiculous to argue over what is and isn't a BCI. It is more important to argue about what methods, technology, therapies, interventions etc. are useful and which ones aren't. A product should be measured on how much it can help a person rather than whether or not it meets some technical definition of a $B C F$ '. Finally, one person said: "I am categorically against categorization. We can certainly waste our breath classifying things as BCI or not BCI, but please let's not try to build towers of logic that build upon that distinction as one of its foundations. That's what philosophers do-philosophy is a fine leisure pastime, but it hinders us more than it helps us in solving concrete practical problems".

Although we authors do not all agree on whether a standard definition is necessary for most stakeholders, we do all agree, as indicated before, that having great variance in the definition of a BCI can be detrimental to the clarity of the ethical debate. Policy makers and the general public will need a clarification of how differences in interpretation bear upon the ethical discussion. Second, $86 \%$ of the respondent would like to see ethical guidelines specific to BCI research and BCI use within 5 years.
More than half of the respondents (57\%) would like to see these guidelines within only 2 years. One respondent cautiously added: "Ethical guidelines for $B C I$ research and use might be useful, but could be detrimental if the guidelines are not comprehensive and thorough". Also Nordmann and Rip pointed out that the field of neural engineering, which is still in its infancy, should avoid the trap of "speculative ethics" [45]. The neuroethical debate should be grounded on thorough knowledge about the technologies under discussion.

Yet, some people do not consider ethical guidelines necessary, since they already exist: "At least the US has well-vetted certification processes for conducting human subjects research. This is a non-issue.... The global rules applied to all human research (including research with locked in patients). Nothing special is needed for BCIs".

Third, we asked respondents if and when a certification process should be set up to determine if a BCI scientist is qualified to work with patients. Sixty-five percent of the respondents think such a certification process should be set up within the next 5 years. This result may reflect the respondents' doubt about which kind of person(s) would be appropriate 
to communicate with the patient and who should be responsible for that (see section "Informed Consent").

Fourth, we asked respondents if and when a certification process should be set up to determine if a product should be dubbed a BCI. More than half of the respondents wanted such a certification process within the next 5 years, but several persons also indicated they either did not know what we meant with a certification process. Additionally persons feel that " $B C I$ researchers don't need their own special certification. The field is too diverse for that to work anyway'.

Fifth, $29.7 \%$ of the respondents would like to have a regular journal devoted solely to BCI research within the next 2 years and $34.1 \%$ within the next 5 years. However, another large group (26.1\%) do not consider a specific journal as an urgent matter. One respondent commented: "I think the journal is unnecessary - if it's good work, it will get into bigger, higher volume journals like Nature or Science or Neuroscience, which helps the field as a whole".

Thus, respondents selected terminological and ethical issues as the most urgent matters from the list we presented to them. Certification procedures for $\mathrm{BCI}$ technology and a journal were regarded as less urgent.

\section{Discussion}

Some Thoughts on the Survey

Here we will discuss how our survey was received by the respondents based on the statistics of their responses and some follow up questions asked at the end of the survey.

First, half of the attendees of the conferences took the time to complete the survey. Several respondents commented at the conference site that they appreciated this study. Some also said the survey itself triggered their awareness about ethical issues in their daily work. Moreover, 103 respondents gave their email address in an optional field of the survey so we could forward any dissemination on these results and 42 skipped this question. Thus, a clear interest among BCI researchers in the issues raised is visible.
Finally, we asked respondents to add any questions they felt we should have included in the survey. These comments help identify the completeness of our survey, and could help improve future efforts. Twenty-eight persons decided to add more questions. 117 skipped this question. We interpret this as a sign we covered relevant issues well. We will discuss some questions respondents suggested us to add. First, one respondent said: "I can't help but notice that no questions were raised about the moral status of using nonhuman animals in testing various BCIs". Indeed, the current survey only assessed opinions about ethical issues related to BCIs which are used as AT for humans with disabilities. An ethical debate on all BCI research would also include debates on BCIs which are used to control prostheses (which typically involves research with invasive recording with animals). In addition, as one respondent commented, also no attention was given to "ethical issues for non-patients". BCI-controlled games are already commercially available and BCI researchers are increasingly applying BCI technologies in gaming or human-computer interaction (HCI) $[43,44,72]$. Ethical, societal and legal issues related to BCI for gaming or HCI may differ greatly from the issues related to BCIs for medical purposes. For example, if BCIs were used to track fatigue levels of air traffic controllers, then issues like workers' rights and privacy of mind may be more imminent topics.

Finally, one respondent (critically?) noted: "When does a questionnaire need to be given to the scientific community?" Two considerations follow from this. First, should such a questionnaire be given to the scientific community at all? And second, how often should you survey opinions? After all, BCI is a relatively new field, and the ethical debate about its applications and implications is still in its infancy. Therefore BCI researchers may not yet have fully developed well-informed opinions about ethical issues. Likewise, ethicists may not yet have thorough knowledge about neurotechnologies and have therefore difficulties to understand what is and what is not possible. Also, in such a rapidly developing field opinions might well change which leads to the question whether surveys should be repeated and if yes, after how much time. 
Despite these reservations, we think this survey was timely, if not a little early, to initiate bridging the gap between the different perspectives existing between neuroengineers (here the BCI community), and also between them and the neuroethicists. Moreover, reflecting on the questions, and the answers they raised, may assist in structuring the growing public debate on BCI. As a caveat, the sample of respondents do not adequately represent all of the researchers working on BCI technologies. For example, no African, SouthAmerican or Australian BCI groups were present at the Asilomar conference, although these groups are also much less prominent in the BCI literature. Also, only twelve respondents in our sample began BCI research before 2000, which implies that other well-established and experienced BCI researchers did not complete the survey. Although, as mentioned before, the field of BCI consists of many young researchers, it remains desirable to repeat a questionnaire of this kind in the near future with different stakeholders.

In addition to our suggestions for conduction new surveys with various improvements, we recommend other future directions. Additional collaborative efforts such as workshops, special sessions, web-based meetings and joint publications (of neuroengineers and ethicists) could introduce and encourage a wider view of different issues. These efforts could work toward ethical guidelines or recommendations with broader distribution and more credibility. Legal issues such as liability, privacy and personal identity should also be explored through appropriate eclectic collaboration.

\section{Final Remarks}

In the introduction, we listed as many as 17 ethical issues that have been identified in the literature. It is not surprising that neurotechnologies like BrainComputer Interfacing raise so many questions. BCIs, like technologies such as DBS or vagal nerve stimulation, confront humanity with issues of existential nature. Who are we? Are we only our brain, and can our brain and personality really be so easily modulated with technologies? Do we want technologies to be inside of our bodies and brains?
On the 10th of November 2010 a Science and Technology Options Assessment (STOA) conference entitled "making perfect life — bioengineering in the 21 st century" was held in the European Parliament. After listening to all the issues that arise with the current merge between information technology, nanotechnology, neuroscience and biology, member of parliament Vitorrio Prodi remarked: "We are living in an era of change where we really need to think ahead in order to protect human dignity." Indeed, while neuroengineering leaps ahead, neuroethical considerations should not lag behind. We strongly support a thorough and continuing ethical debate on neurotechnologies that involves contributors from neuroengineering, neuroscience, neuroethics, philosophy, politics, journalism and the general public. Resources should be made available for this ethical debate. Van Keulen and Schuijff comment: "it is remarkable that, unlike with emerging technologies like synthetic biology and nanotechnology, the EU is not yet funding any large ethical, legal and/or sociological project in neurosciences, or in neural engineering for that matter" (p. 123;[63]). We recognize that there are many issues that need further exploration even after this survey, but hope our paper encourages such further discussion.

Acknowledgements The authors gratefully acknowledge the support of the BrainGain Smart Mix Program of the Ministry of Economic Affairs and the Ministry of Education, Culture and Science of the Netherlands, the Netherlands. This work was also supported by the Information and Communication Technologies Coordination and Support action "FutureBNCI", Project number ICT- 2010-248320. We would like to thank the staff of FatronikTecnalia and the BrainGain members, in particular Rutger Vlek, at the Radboud University (Nijmegen), many of whom not only took the time to answer all questions, but in addition gave many useful comments. Most strongly, of course, we thank all respondents who took the time to complete the survey in Asilomar. We appreciate that you gave your time and effort even though several social events were taking place in non-conference time. Also many thanks to the organizers of the 4th international BCI conference, Theresa Vaughan, Mary-Jane Schneider and Jonathan Wolpaw, for allowing us to recruit respondents at the conference and to the anonymous reviewer for helpful comments.

Open Access This article is distributed under the terms of the Creative Commons Attribution Noncommercial License which permits any noncommercial use, distribution, and reproduction in any medium, provided the original author(s) and source are credited. 


\section{Appendix 1}

\section{Monterey BCl survey REVISED 1. 2010 MONTEREY BCI STUDY}

Thank you for taking the time to complete this survey.

AIM

This study aims to provide a systematic review of opinions of contributors to the $\mathrm{BCl}$ field. Since you are an expert in your field and you have experience working with $\mathrm{BCls}$ we strongly believe that your contribution is valuable. The results from this survey may serve all $\mathrm{BCl}$ scientists in understanding the future direction of our research. The results may also serve to inform the general public and public funding institutions about $\mathrm{BCls}$.

\section{WHAT IS THE SURVEY ABOUT?}

We will ask questions about the terminology and definitions of $\mathrm{BCls}$. Also, we will ask you when you expect different types of $\mathrm{BCls}$ to be ready for the market. In addition, we will ask you to evaluate some statements about ethical issues related to $\mathrm{BCl}$ use.

\section{PRIVACY}

We have a paper and pencil version and an internet version available for you. You are ${ }^{*}$ not ${ }^{\star}$ required to fill out your name anywhere, except if you want to. The internet version of the survey does automatically store your IP address, but we will not use these data.

\section{PARTICIPATION}

Of course your participation is voluntary and you can quit the survey any time.

\section{TIME NEEDED}

We estimate that you will need 10-20 minutes to complete this survey. Unfortunately the internet version requires that you complete the survey in one visit. If you prefer to fill out the survey in spare moments over a couple of days we advise you to ask for a paper version.

\section{RESPONSIBLE TEAM:}

The survey is the joint effort of six people:

- Femke Nijboer, Fatronik Tecnalia, Health and Quality of Life Unit, San Sebastián, Spain.

- Pim Haselager, Radboud University Nijmegen, Donders Institute for Brain, Cognition and Behaviour, Nijmegen, The Netherlands

- Jens Clausen, Institute of Ethics and History in Medicine, University of Tübingen, Tübingen, Germany

- Brendan Allison, Graz University of Technology, Graz, Austria

- Mary-Jane Schneider, Department of Health Policy, Management and Behavior School of Public Health, University of Albany

- Theresa Vaughan, Laboratory of Nervous System Disorders, Wadsworth Center, New York State Department of Health

\section{CONTACT PERSON}

The contact person at the conference is Femke Nijboer. Feel free to contact her when you have questions or doubts about the survey. You can also send her an email: femke.nijboer@gmail.com. 


\section{Monterey $\mathrm{BCl}$ survey REVISED}

\section{GENERAL INFORMATION}

Before we start we would like to ask you some general questions about yourself.

\section{What's your gender?}
O male
female

\section{What's you age?}
$\Gamma<18$ years
Г 18-30 years
Г 31-55 years
Г 56-70 years
$\Gamma>70$ years

\section{What's your profession or occupation? (you can choose more than one)}
$\Gamma$ graduate student
$\lceil\mathrm{PhD}$ student
Г $\mathrm{BCl}$ user
$\Gamma$ neuroscientist
$\Gamma$ cognitive scientist
$\Gamma$ medical doctor
$\lceil$ psychologist
「 physiotherapist
$\Gamma$ occupational therapist
$\Gamma$ mechanical engineer
$\lceil$ electrical engineer
$\lceil$ computer scientist
$\lceil\quad$ Al researcher
$\lceil$ philosopher
$\Gamma$ ethicist
$\lceil$ marketing manager
$\lceil$ business manager
$\lceil$ salesperson
「 journalist
$\Gamma$ other

Other (please specify)

4. How many years of experience do you have in this profession / occupation? 


\section{Monterey $\mathrm{BCl}$ survey REVISED}

5. How many hours per week do you think you spend working with $\mathrm{BCls}$ ?
I practically never work with $\mathrm{BCls}$
1-8 hours
9-16 hours
(17-24 hours
25-32 hours
(C) $33-40$ hours
More than 40 hours per week

6. In which year did you start with $\mathrm{BCl}$ research (please choose a year between between 1900 and 2010)

7. Where do you live and perform this occupation?

Asia

Australia

Europe

Africa

South-America

C North-America 


\section{Monterey $\mathrm{BCl}$ survey REVISED}

\section{QUESTIONS ABOUT TERMINOLOGY}

We would like to ask you some questions about terminology related to systems that measure signals from the central nervous system and "translate" those signals into output signals. Various names have been used to refer to such a system. Here we want to understand what your preferences and opinions are about current terminology.

\section{Which name has your preference to describe such systems?}

Brain-Computer Interface $(\mathrm{BCl})$

Brain-Machine Interface (BMI)

Direct Neural Interface

Brain/neuronal Computer Interaction (BNCl)

Other (please specify)

2. For convenience's sake we'll use the term "BCl" in the rest of this questionnaire . Please indicate whether or not you think that the examples we list below can be referred to as a $\mathrm{BCl}$ or tell us if you don't know.

\begin{tabular}{|c|c|c|c|}
\hline & This is a $\mathrm{BCl}$ & This is NOT a BCl & I don't know \\
\hline $\begin{array}{l}\text { Cursor control based on } \\
\text { self-regulation of slow } \\
\text { cortical potentials in the } \\
\text { EEG }\end{array}$ & C & $\mathrm{O}$ & C \\
\hline $\begin{array}{l}\text { Orthosis control based on } \\
\text { the self-regulation of mu } \\
\text { rhythm in the EEG }\end{array}$ & 0 & 0 & $\mathrm{O}$ \\
\hline $\begin{array}{l}\text { Fatigue monitor for drivers } \\
\text { in a car based on brain } \\
\text { signals }\end{array}$ & 0 & O & $\mathrm{C}$ \\
\hline $\begin{array}{l}\text { Offline alertness tool to } \\
\text { assess workers }\end{array}$ & 0 & $\mathrm{O}$ & 0 \\
\hline $\begin{array}{l}\text { Adaptation of avatar to } \\
\text { emotion of user in a } \\
\text { virtual game }\end{array}$ & 0 & 0 & $\mathrm{O}$ \\
\hline EEG lie detector & O & 0 & O \\
\hline Deep brain stimulator & O & $\mathrm{O}$ & $\mathrm{O}$ \\
\hline $\begin{array}{l}\text { Image detection; whether } \\
\text { a recently presented } \\
\text { object stands out }\end{array}$ & 0 & 0 & 0 \\
\hline Retinal implant & C & O & O \\
\hline $\begin{array}{l}\text { Neuromarketing; } \\
\text { classification of brain } \\
\text { responses to } \\
\text { advertisements or new } \\
\text { products }\end{array}$ & 0 & 0 & 0 \\
\hline Remote controlled rat & $\mathrm{C}$ & O & $\mathrm{O}$ \\
\hline
\end{tabular}




\section{Monterey $\mathrm{BCl}$ survey REVISED}

\section{In your opinion, which of these devices is a $\mathrm{BCl}$ ? (you may choose more than one)}

Evoked / reactive: the user is presented with stimuli and performs voluntary mental tasks that affect the brain's activity elicited by these stimuli (e.g. systems based on P300 or SSVEP activity)

- Spontaneous / active: the user voluntary regulates brain activity that is not directly elicited by an external stimulus (e.g. systems based on mu rhythm or ERD or SCP activity)

- Emotive / passive: the system detects brain activity that the user produces involuntarily and adapts some form of human-computer interaction to this detection (e.g. frustration, confusion, sleep, depth of anesthesia)

\section{In your opinion, which of these elements is REQUIRED for a $\mathrm{BCI}$ ? (you may choose more than one)}

- Must detect brain activity directly (without using signals from peripheral nerves or muscles)

「 Must classify brain activity

— Provides feedback to the user that reflects whether s/he successfully attained a goal

- Provides feedback in realtime, or neartime

- User must choose to send a signal each time (that is, the device does not rely solely on signals that the user produces for other reasons than using the $\mathrm{BCl}$ )

- Must be solely for the purpose of sending a message or command (as opposed to rehabilitation, monitoring, pure research, etc.)

Other (please specify)

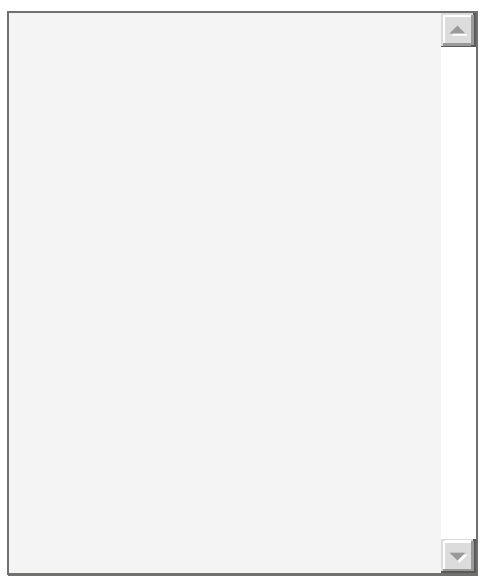




\section{Monterey $\mathrm{BCl}$ survey REVISED}

\section{Marketability of BCls}

Here we would like to know your expectations of the time needed before the $\mathrm{BCl}$ can enter the commercial market. For convenience's sake we have ordered some $\mathrm{BCl}$ types based on their function:

\section{BCls FOR HEALTHY USERS}

This type of $\mathrm{BCl}$ is used by healthy users.

\section{BCIs AS ASSISTIVE TECHNOLOGY}

This type of $\mathrm{BCl}$ provides compensation for loss of motor function. For example, a $\mathrm{BCl}$-controlled communication program or $\mathrm{BCl}$-controlled wheelchair.

\section{BCI-CONTROLLED PROSTHESES}

This type of $\mathrm{BCl}$ aims restores motor function by replacing a paralyzed limb by a prosthesis. For example, a $\mathrm{BCl}-$ controlled robotic arm or leg.

\section{BCls AS THERAPY TOOLS}

Here we consider $\mathrm{BCls}$ that serve as temporary tools to allow people with psychological/neurological disorders to directly use feedback of their brain activity for training/recovery purposes. For example, neurofeedback of sensorimotor rhythms may promote brain recovery after stroke. Another example may be the promotion of better attention allocation through slow cortical potential training.

\section{When do you expect a $\mathrm{BCl}$ for healthy users to become available on the market?}
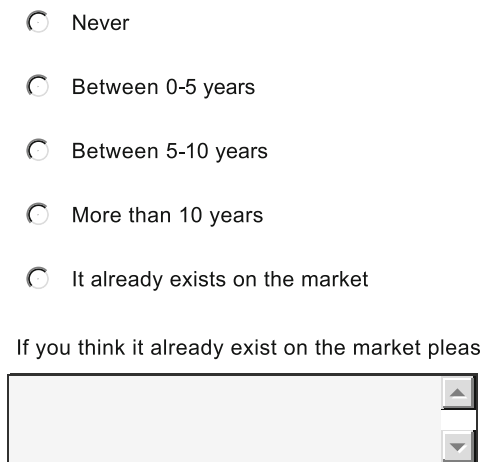

\section{When do you expect a $\mathrm{BCl}$ as assistive technology to become available on the market?}
Never
Between $0-5$ years
Between $5-10$ years
More than 10 years
It already exists on the market

If you think it already exist on the market please comment which group or company offers it 


\section{Monterey BCl survey REVISED}

3. When do you expect a $\mathrm{BCl}$-controlled prostheses to become available on the market?

Never

Between $0-5$ years

Between $5-10$ years

More than 10 years

It already exists on the market

If you think it already exist on the market please comment which group or company offers it

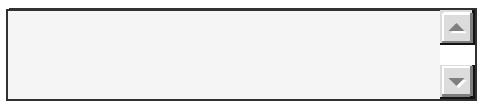

4. When do you expect $\mathrm{BCls}$ as therapy tools to become available on the market?

Never

Between $0-5$ years

Between $5-10$ years

More than 10 years

It already exists on the market

If you think it already exist on the market please comment which group or company offers it

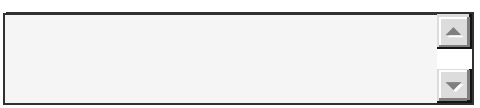




\section{Monterey $\mathrm{BCI}$ survey REVISED}

\section{ETHICAL ISSUES RELATED TO BCI AS ASSISTIVE TECHNOLOGY}

Here we present you with some statements which are related to ethical issues. You may or may not have thought about such issues, but please indicate to which extent you feel you agree with following statements related to $\mathrm{BCls}$ as assistive technology. If you don't know, you may indicate this as well.

1. Informed consent is the process in which a participant of the legal representative of the participant is fully informed about the study he or she entering and legally agrees to participation. Some people may need a legal representative due to communication problems.

Please indicate to which extent you agree with the following statements about informed consent of users for $\mathrm{BCl}$ studies that aim to develop assistive technology.

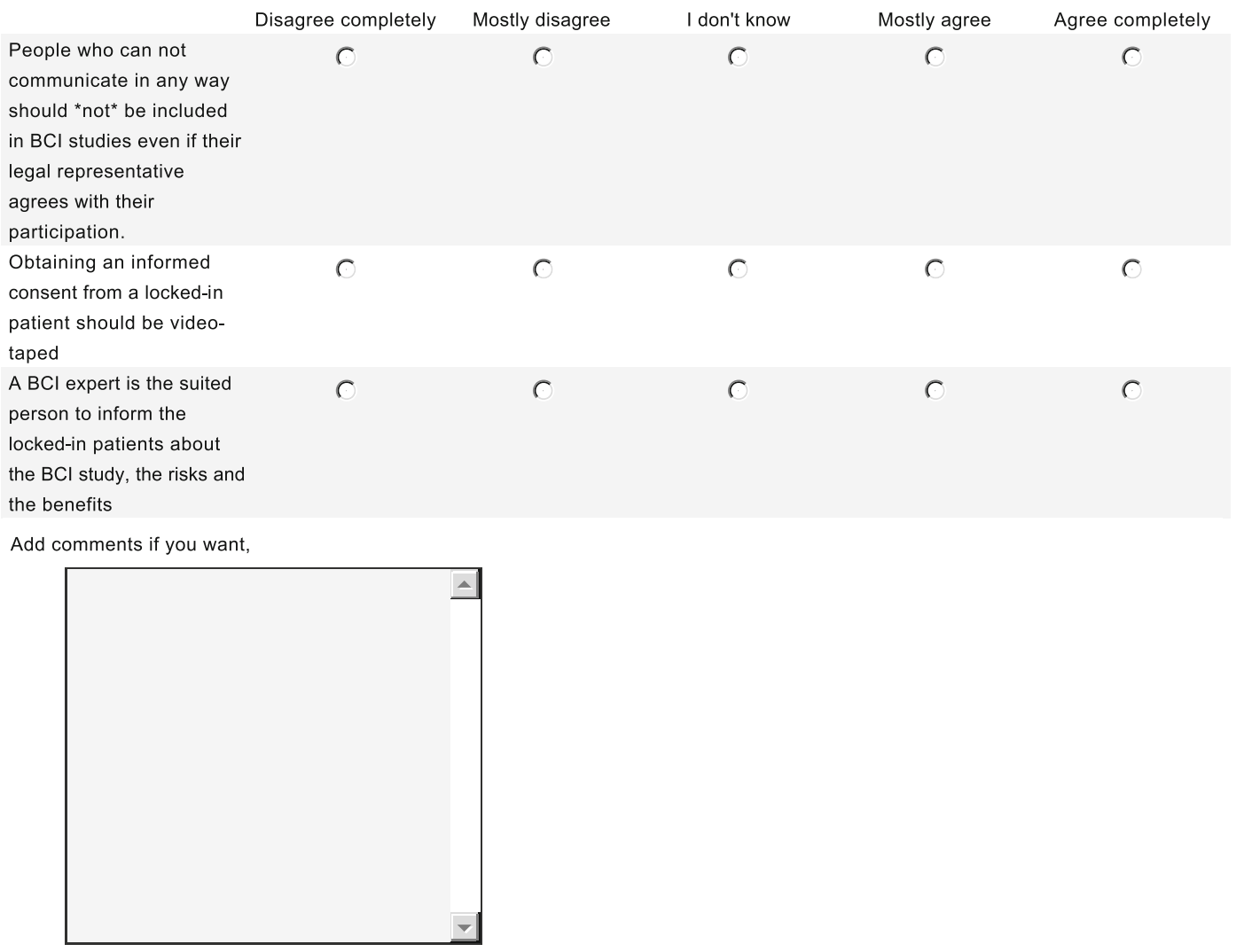




\section{Monterey BCI survey REVISED}

2. Please indicate to which extent you agree with the following statements which also deal with informed consent
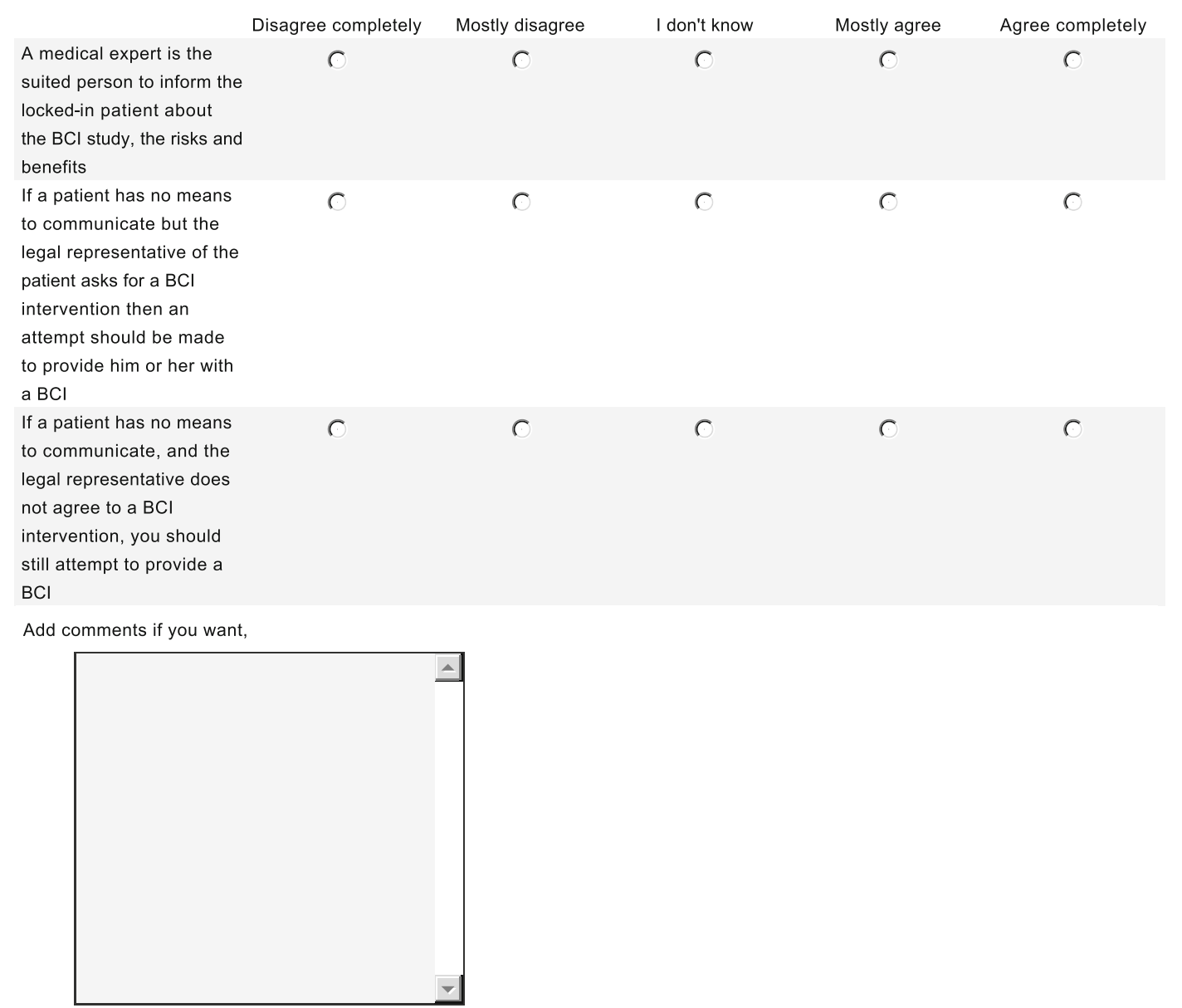


\section{Monterey $\mathrm{BCl}$ survey REVISED}

3. Please indicate to which extent you agree with the following statements about risks and benefits of $\mathrm{BCls}$ as assistive technology

\begin{tabular}{|c|c|c|c|c|c|}
\hline & Disagree completely & Mostly disagree & I don't know & Mostly agree & Agree completely \\
\hline $\begin{array}{l}\text { The current benefits } \\
\text { outweigh the current risks } \\
\text { of non-invasive } \mathrm{BCl} \text { for } \\
\text { locked-in patients }\end{array}$ & c & C & 0 & C & C \\
\hline $\begin{array}{l}\text { The risks of non-invasive } \\
\mathrm{BCls} \text { are still largely } \\
\text { unknown }\end{array}$ & 0 & 0 & 0 & 0 & 0 \\
\hline $\begin{array}{l}\text { The current benefits } \\
\text { outweigh the current risks } \\
\text { of invasive } \mathrm{BCl} \text { for locked- } \\
\text { in patients }\end{array}$ & 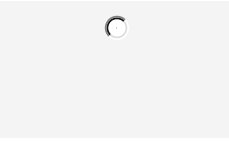 & 0 & 0 & 0 & 0 \\
\hline $\begin{array}{l}\text { The risks of invasive } \mathrm{BCls} \\
\text { are still largely unknown }\end{array}$ & 0 & 0 & 0 & 0 & 0 \\
\hline
\end{tabular}

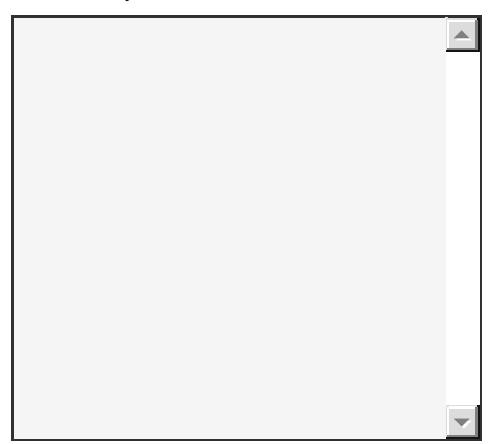




\section{Monterey $\mathrm{BCl}$ survey REVISED}

4. $\mathrm{BCl}$ research is the joint effort of a $\mathrm{BCl}$ team which consist of people from several disciplines, with different statuses and beliefs about $\mathrm{BCls}$, risks and benefits.

Participants and patients entering studies often interact with several team members. Please indicate to which extent you agree with the following statements about team responsibility.

All BCl teams should have Completely disagree Mostly disagree
1 common code with rules
\& regulations for team
responsibility issues
It is okay when a patient
hears about the difference
of opinion of various team
members considering the
risks and the benefits of a
BCl
BCl teams should stick to
one risk/benefit analysis
and tell this to the patient
Add comments if you want,




\section{Monterey BCl survey REVISED}

5. Please indicate to which extent you agree with the following statements regarding the consequences of a $\mathrm{BCl}$ for the patient's life and the life of his family members

A BCl as assistive
technology will be a
reason for a patient to
change his or her end-of-
life decisions

Add comments if you want,

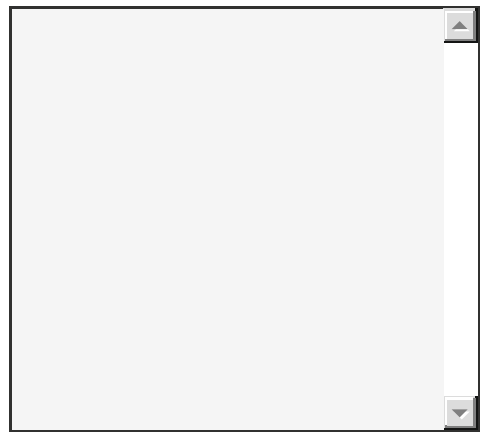




\section{Monterey $\mathrm{BCl}$ survey REVISED}

6. The use of BCls may change the way a person sees him- or herself. The use of $\mathrm{BCls}$ may also lead to harm done with the device (imagine for example you hit someone else while driving your $\mathrm{BCl}$-controlled wheelchair). Please indicate to which extent you agree with the following statements regarding the effect of a $\mathrm{BCl}$ as assistive technology on the personhood and the responsibility of the user.

$\mathrm{BCl}$ users are responsible
for the actions they
execute and the messages
they transmit with the
device
$\begin{aligned} & \text { BCls as assistive } \\ & \text { technology could lead to } \\ & \text { behaviors uncharacteristic } \\ & \text { of the user's personal } \\ & \text { identity } \\ & \text { BCls as assistive } \\ & \text { technology will not } \\ & \text { change a person's identity } \\ & \text { Add comments if you want, }\end{aligned}$




\section{Monterey $\mathrm{BCl}$ survey REVISED}

7. $\mathrm{BCl}$ research often receives the attention of the media. $\mathrm{BCl}$ researchers may be asked to answer questions of journalists, appear in tv shows or be part of documentaries. Please indicate to which extent you agree with the following statements regarding the media attention for $\mathrm{BCls}$
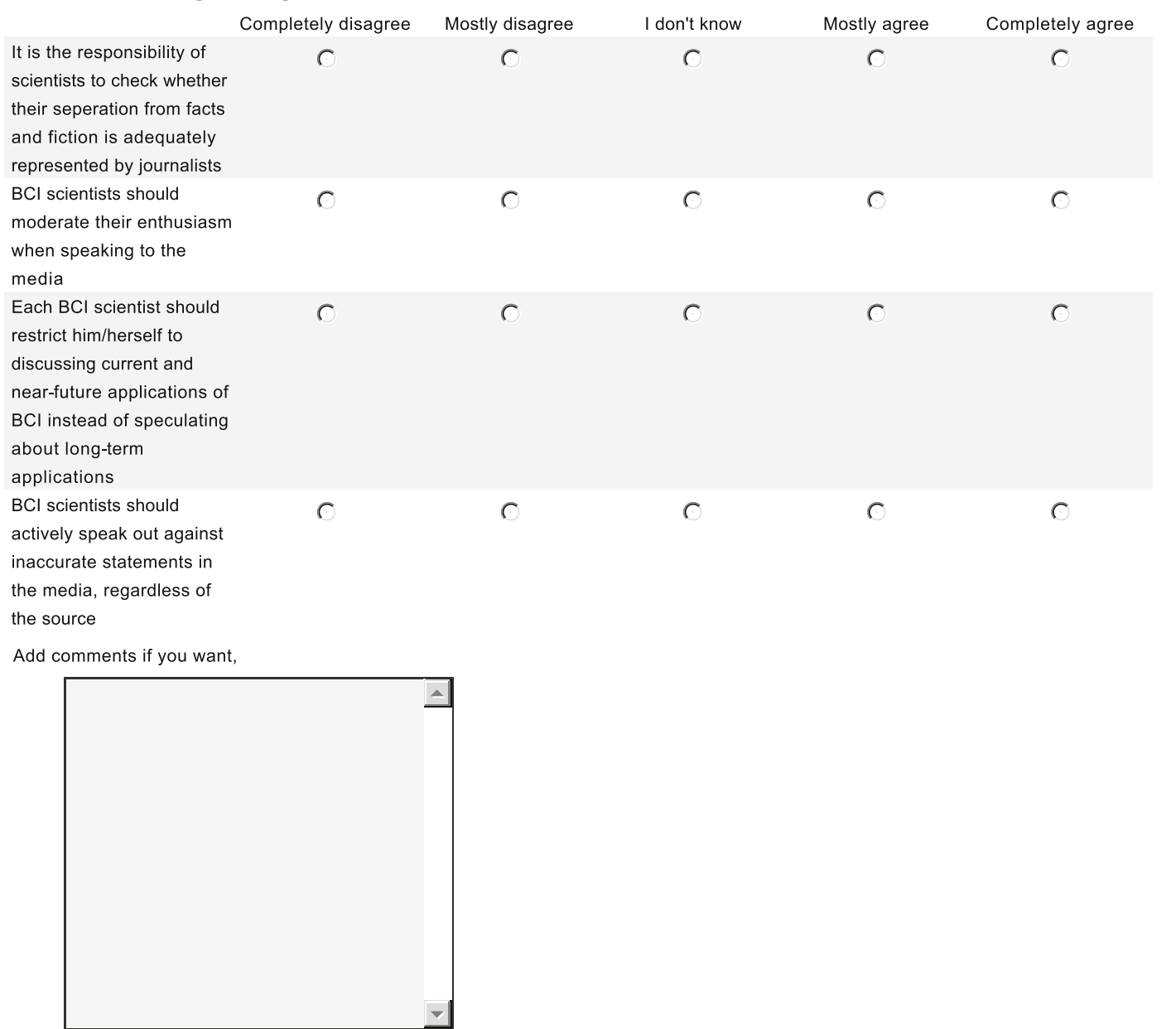


\section{Monterey $\mathrm{BCl}$ survey REVISED}

\section{MATTERS OF URGENCY}

Finally, we want your opinion about which issues you consider most urgent.

\section{Please indicate in what period the items listed belowed need to be settled.}

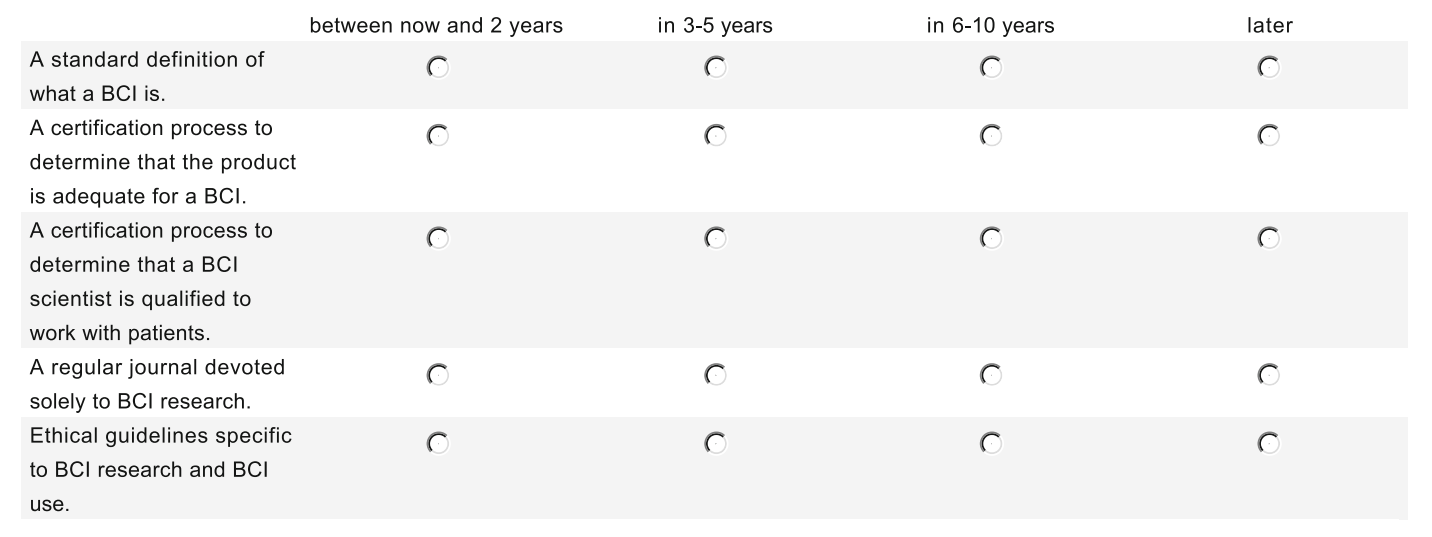

Other (please specify)

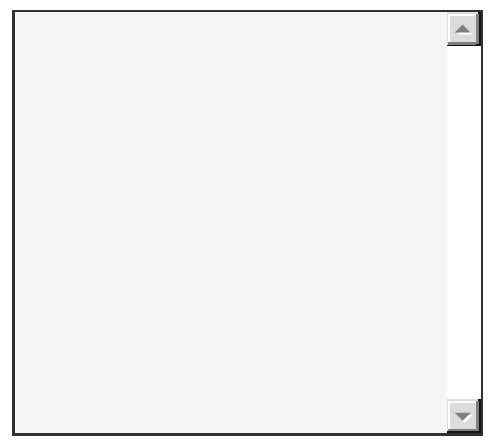

2. In your opinion, which question(s) did we not ask that we should have asked?

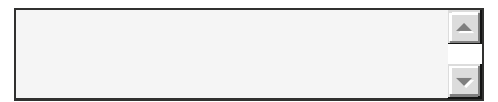




\section{Monterey BCI survey REVISED}

\section{THANK YOU !!}

We would like to thank you for filling out this survey. We know we have asked a lot of effort and time from you so we really appreciate your participation. We are convinced that your answers help the $\mathrm{BCl}$ community to be better prepared for the future.

The following questions do not need to be answered, but if you want you can tell us your name and email adress and indicate if you want to be informed about the publication of these results.

1. If you want to receive a notice when these results are published please tell us your name and email address

Name:

Email Address:

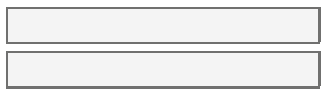

2. Finally, would you be interested to receive an invitation when we decide to develop another BCl-related survey?
no
yes 


\section{References}

1. Alleyne, R. 2010. Mind-reading machine' can convert thoughts into speech. The Telegraph. http://www.telegraph. co.uk/science/science-news/7987821/Mind-readingmachine-can-convert-thoughts-into-speech.html. Accessed 8 September 2010.

2. Allison, B.Z., C. Brunner, V. Kaiser, G.R. Muller-Putz, C. Neuper, and G. Pfurtscheller. 2010. Toward a hybrid braincomputer interface based on imagined movement and visual attention. Journal of Neural Engineering 7(2): 26007. doi:10.1088/1741-2560/7/2/026007.

3. Allison, B.Z. 2011. The fringes of neurotechnology. In Fringe science, ed. K. Grazier, L. Wilson, and H. Butterfield. Houston: BenBella Press.

4. Allison, Brendan Z. 2010. Toward Ubiquitous BCIs. In Braincomputer interfaces, ed. Bernhard Graimann, Gert Pfurtscheller, and Brendan Allison, 357-387. Berlin, Heidelberg: SpringerVerlag Heidelberg.

5. Allison, Brendan Z., and Christa Neuper. 2010. Could anyone use a BCI? In Brain-computer interfaces, ed. Desney S. Tan and Anton Nijholt, 35-54. Springer London: Human-Computer Interaction Series.

6. Birbaumer, N., N. Ghanayim, T. Hinterberger, I. Iversen, B. Kotchoubey, A. Kubler, J. Perelmouter, E. Taub, and H. Flor. 1999. A spelling device for the paralysed. Nature 398 (6725): 297-298.

7. Chatrian, G.E., M.C. Petersen, and J.A. Lazarte. 1959. The blocking of the rolandic wicket rhythm and some central changes related to movement. Electroencephalography and Clinical Neurophysiology. Supplement 11 (3): 497-510.

8. Clausen, J. 2008. Moving minds: ethical aspects of neural motor prostheses. Biotechnology Journal 3(12): 14931501. doi:10.1002/biot.200800244.

9. Clausen, J. 2009. Man, machine and in between. Nature 457(7233): 1080-1081. doi:10.1038/4571080a.

10. Clausen, J. 2010. Ethical brain stimulation - neuroethics of deep brain stimulation in research and clinical practice. The European Journal of Neuroscience 32(7): 1152-1162. doi:10.1111/j.1460-9568.2010.07421.x.

11. Computers that read your mind. 2006. The economist. http://www.economist.com/node/7904258. Accessed 21 September 2006.

12. Demetriades, A.K., C.K. Demetriades, C. Watts, and K. Ashkan. 2010. Brain-machine interface: the challenge of neuroethics. The Surgeon 8(5): 267-269. doi:10.1016/j. surge.2010.05.006.

13. Dobkin, B.H. 2007. Brain-computer interface technology as a tool to augment plasticity and outcomes for neurological rehabilitation. The Journal of Physiology 579(Pt 3): 637-642. doi:10.1113/jphysiol.2006.123067.

14. Donchin, E. 1966. A multivariate approach to the analysis of average evoked potentials. IEEE Transactions on Biomedical Engineering 13(3): 131-139.

15. Donchin, E. 1969. Discriminant analysis in average evoked response studies: the study of single trial data. Electroencephalography and Clinical Neurophysiology 27(3): 311-314.

16. Editorial. 2006. Neuroethics needed. Nature 441(7096): 907. doi:10.1038/441907a.
17. Fenton, A., and S. Alpert. 2008. Extending our view on using BCIs for locked-in syndrome. Neuroethics 1: 119132. doi:10.1007/s12152-008-9014-8.

18. Fetz, E.E. 1969. Operant conditioning of cortical unit activity. Science 163(870): 955-958.

19. Fetz, E.E., and D.V. Finocchio. 1971. Operant conditioning of specific patterns of neural and muscular activity. Science 174(7): 431-435.

20. Fetz, E.E., and A.R. Wyler. 1973. Operantly conditioned firing patterns of epileptic neurons in the monkey motor cortex. Experimental Neurology 40(3): 586-607.

21. Ghosh, P. 2010. Dream recording device 'possible' researcher claims. BBC News Science \& Environment. http://www.bbc.co.uk/news/science-environment11635625. Accessed 27 October 2010.

22. Haselager, P., R. Vlek, J. Hill, and F. Nijboer. 2009. A note on ethical aspects of BCI. Neural Networks 22(9): 13521357. doi:10.1016/j.neunet.2009.06.046.

23. Hoffmann, U., J.M. Vesin, T. Ebrahimi, and K. Diserens. 2008. An efficient P300-based brain-computer interface for disabled subjects. Journal of Neuroscience Methods 167(1): 115-125.

24. Klaming, Laura, and Pim Haselager. 2010. Did My Brain Implant Make Me Do It? Questions Raised by DBS Regarding Psychological Continuity, Responsibility for Action and Mental Competence. Neuroethics 1-13. doi:10.1007/s12152-010-9093-1.

25. Kübler, A., F. Nijboer, J. Mellinger, T.M. Vaughan, H. Pawelzik, G. Schalk, D.J. McFarland, N. Birbaumer, and J. R. Wolpaw. 2005. Patients with ALS can use sensorimotor rhythms to operate a brain-computer interface. Neurology 64(10): 1775-1777.

26. Kübler, A., S. Winter, and N. Birbaumer. 2003. The Thought Translation Device: Slow cortical potential biofeedback for verbal communication in paralysed patients. In Biofeedback - a practitioner's guide, ed. M. S. Schwartz and F. Andrasik, 471-481. New York: Guilford Press.

27. Kubler, A., and N. Birbaumer. 2008. Brain-computer interfaces and communication in paralysis: extinction of goal directed thinking in completely paralysed patients? Clinical Neurophysiology 119(11): 2658-2666. doi:10.1016/j.clinph.2008.06.019.

28. Kurt, A., F. Nijboer, T. Matuz, and A. Kubler. 2007. Depression and anxiety in individuals with amyotrophic lateral sclerosis: epidemiology and management. CNS Drugs 21(4): 279-291.

29. Laureys, S., F. Pellas, P. Van Eeckhout, S. Ghorbel, C. Schnakers, F. Perrin, J. Berre, et al. 2005. The locked-in syndrome: what is it like to be conscious but paralyzed and voiceless? Progress in Brain Research 150: 495-511. doi:10.1016/S0079-6123(05)50034-7.

30. Leeb, R., H. Sagha, R. Chavarriaga, and R. Millan Jdel. 2011. A hybrid brain-computer interface based on the fusion of electroencephalographic and electromyographic activities. Journal of Neural Engineering 8(2): 025011. doi:10.1088/1741-2560/8/2/025011.

31. Liberman, R.P., D.M. Hilty, R.E. Drake, and H.W. Tsang. 2001. Requirements for multidisciplinary teamwork in psychiatric rehabilitation. Psychiatric Services 52(10): 1331-1342. 
32. Lulé, D., S. Hacker, A. Ludolph, N. Birbaumer, and A. Kubler. 2008. Depression and quality of life in patients with amyotrophic lateral sclerosis. Deutsches Arzteblatt international 105(23): 397-403.

33. Lutzenberger, W., N. Birbaumer, Th Elbert, B. Rockstroh, W. Bippus, and R. Breidt. 1980. Self-regulation of slow cortical potentials in normal subjects and patients with frontal lobe lesions. Progresses in Brain Research 54: 427430.

34. Lutzenberger, W., T. Elbert, B. Rockstroh, and N. Birbaumer. 1979. The effects of self-regulation of slow cortical potentials on performance in a signal detection task. International Journal of Neuroscience 9(3): 175-183.

35. Mason, S.G., A. Bashashati, M. Fatourechi, K.F. Navarro, and G.E. Birch. 2007. A comprehensive survey of brain interface technology designs. Annals of Biomedical Engineering 35(2): 137-169. doi:10.1007/s10439-006-9170-0.

36. Matuz, T. 2008. Betreuungsstrategien für schwerstgelähmte Patienten: empirische Ethik und neurowissenschaftliche Ansätze Eberhard-Karls-Universität Tübingen, Tübingen.

37. Millan, J.D., R. Rupp, G.R. Muller-Putz, R. Murray-Smith, C. Giugliemma, M. Tangermann, C. Vidaurre, et al. 2010. Combining brain-computer interfaces and assistive technologies: state-of-the-art and challenges. Frontiers in Neuroscience 4. doi:10.3389/fnins.2010.00161.

38. Neuper, C., G.R. Müller, A. Kübler, N. Birbaumer, and G. Pfurtscheller. 2003. Clinical application of an EEG-based brain-computer interface: a case study in a patient with severe motor impairment. Clinical Neurophysiology 114(3): 399-409.

39. Nijboer, F., E.W. Sellers, J. Mellinger, M.A. Jordan, T. Matuz, A. Furdea, S. Halder, et al. 2008. A P300-based brain-computer interface for people with amyotrophic lateral sclerosis. Clinical Neurophysiology 119(8): 19091916. doi:10.1016/j.clinph.2008.03.034.

40. Nijboer, F., J. Clausen, B. Z. Allison, and P. Haselager. in press. Researchers' opinions about ethically sound dissemination of BCI research to the public media. International Journal of Bioelectromagnetism.

41. Nijboer, Femke, Niels Birbaumer, and Andrea Kübler. 2010. The influence of psychological state and motivation on brain-computer interface performance in patients with amyotrophic lateral sclerosis - a longitudinal study. Frontiers in Neuroprosthetics 4. doi:10.3389.fnins.2010.00055.

42. Nijboer, Femke, and Ursula Broermann. 2010. Braincomputer interfaces for communication and control in locked-in patients. In Brain-Computer Interfaces, ed. Bernhard Graimann, Gert Pfurtscheller, and Brendan Allison, 185-201. Berlin, Heidelberg: Springer-Verlag Heidelberg.

43. Nijholt, A., D. Plass-Oude Bos, and B. Reuderink. 2009. Turning shortcomings into challenges: brain-computer interfaces for games. Entertainment Computing 1(2): 85-94.

44. Nijholt, Anton. 2009. BCI for games: a 'State of the Art' survey. In Entertainment Computing - ICEC 2008, ed. Scott Stevens and Shirley Saldamarco, 225-228. Springer Berlin/ Heidelberg: Lecture Notes in Computer Science.

45. Nordmann, A., and A. Rip. 2009. Mind the gap revisited. Nature Nanotechnology 4(5): 273-274. doi:10.1038/ nnano.2009.26.
46. New York Times. 2010. Communicating with a patient in a vegetative state. February 4.

47. Pfurtscheller, G., B.Z. Allison, C. Brunner, G. Bauernfeind, T. Solis-Escalante, R. Scherer, T.O. Zander, G. Mueller-Putz, C. Neuper, and N. Birbaumer. 2010. The hybrid BCI. Frontiers in Neuroscience 4: 30. doi:10.3389/fnpro.2010.00003.

48. Phillips 2nd, L.H. 2006. Communicating with the "locked-in" patient: because you can do it, should you? Neurology 67(3): 380-381. doi:10.1212/01.wnl.0000232725.28806.79.

49. Pineda, J.A., and E. Hecht. 2009. Mirroring and mu rhythm involvement in social cognition: are there dissociable subcomponents of theory of mind? Biological Psychology 80(3): 306-314. doi:10.1016/j.biopsycho.2008.11.003.

50. Racine, E., S. Waldman, N. Palmour, D. Risse, and J. Illes. 2007. "Currents of hope": neurostimulation techniques in U.S. and U.K. print media. Camb Q Healthc Ethics 16(3): 312-316.

51. Racine, E., S. Waldman, J. Rosenberg, and J. Illes. 2010. Contemporary neuroscience in the media. Social Science \& Medicine. doi:10.1016/j.socscimed.2010.05.017.

52. Robbins, R.A., Z. Simmons, B.A. Bremer, S.M. Walsh, and S. Fischer. 2001. Quality of life in ALS is maintained as physical function declines. Neurology 56(4): 442-444.

53. Schalk, G. 2008. Brain-computer symbiosis. Journal of Neural Engineering 5(1): P1-P15. doi:10.1088/1741-2560/5/1/P01.

54. Schermer, M. 2009. The mind and the machine. On the conceptual and moral implications of brain-machine interaction. Nanoethics 3(3): 217-230. doi:10.1007/s11569009-0076-9.

55. Sellers, E.W., T.M. Vaughan, and J.R. Wolpaw. 2010. A brain-computer interface for long-term independent home use. Amyotrophic Lateral Sclerosis. doi:10.3109/ 17482961003777470 .

56. Shanawani, H., M.D. Wenrich, M.R. Tonelli, and J.R. Curtis. 2008. Meeting physicians' responsibilities in providing end-of-life care. Chest 133(3): 775-786. doi:10.1378/ chest.07-2177.

57. Silvoni, S., C. Volpato, M. Cavinato, M. Marchetti, K. Priftis, A. Merico, P. Tonin, K. Koutsikos, F. Beverina, and F. Piccione. 2009. P300-based brain-computer interface communication: evaluation and follow-up in amyotrophic lateral sclerosis. Frontiers in Neuroscience 3: 60. doi:10.3389/neuro.20.001.2009.

58. Simmons, Z., B.A. Bremer, R.A. Robbins, S.M. Walsh, and S. Fischer. 2000. Quality of life in ALS depends on factors other than strength and physical function. Neurology 55(3): 388-392.

59. Surmeli, T., and A. Ertem. 2009. QEEG guided neurofeedback therapy in personality disorders: 13 case studies. Clinical EEG and Neuroscience 40(1): 5-10.

60. Synofzik, M., and T.E. Schlaepfer. 2008. Stimulating personality: ethical criteria for deep brain stimulation in psychiatric patients and for enhancement purposes. Biotechnology Journal 3(12): 1511-1520. doi:10.1002/biot.200800187.

61. Tamburrini, G. 2009. Brain to computer communication: ethical perspectives on interaction models. Neuroethics 2 (3): 137-149.

62. Townsend, G., B.K. LaPallo, C.B. Boulay, D.J. Krusienski, G.E. Frye, C.K. Hauser, N.E. Schwartz, T.M. Vaughan, J.R. Wolpaw, and E.W. Sellers. 2010. A novel P300-based braincomputer interface stimulus presentation paradigm: moving 
beyond rows and columns. Clinical Neurophysiology 121 (7): 1109-1120. doi:10.1016/j.clinph.2010.01.030.

63. van Est, R., D. Stemerding, I. van Keulen, I. Geesink, and M. Schuijff. 2010. Making perfect life - bioengineering (in) the 21st century, Interim Study Monitoring report - Phase II, ed. Legislative coordinations and conciliations: ETAG.

64. Vaughan, T.M., D.J. McFarland, G. Schalk, W.A. Sarnacki, D.J. Krusienski, E.W. Sellers, and J.R. Wolpaw. 2006. The Wadsworth BCI research and development program: At home with BCI. IEEE Transactions on Neural Systems and Rehabilitation Engineering 14(2): 229-233.

65. Walsh, F. 2010. Vegetative state patients can respond to questions BBC News Health. http://news.bbc.co.uk/2/hi/ 8497148.stm. Accessed 3 February 2010.

66. Walter, Sven. 2010. Locked-in syndrome, BCI, and a confusion about embodied, embedded, extended, and enacted cognition. Neuroethics 3(1): 61-72.

67. Walter, W.G. 1964. The contingent negative variation: an electrocortical sign of significant association in the human brain. Science 146: 434.
68. Wilhelm, B., M. Jordan, and N. Birbaumer. 2006. Communication in locked-in syndrome: effects of imagery on salivary pH. Neurology 67: 534-535.

69. Wolpaw, J.R., N. Birbaumer, D.J. McFarland, G. Pfurtscheller, and T.M. Vaughan. 2002. Brain-computer interfaces for communication and control. Clinical Neurophysiology 113 (6): 767-791.

70. Wolpaw, J.R., D.J. McFarland, G.W. Neat, and C.A. Forneris. 1991. An EEG-based brain-computer interface for cursor control. Electroencephalography and Clinical Neurophysiology 78(3): 252-259.

71. Zander, T.O., and C. Kothe. 2011. Towards passive braincomputer interfaces: applying brain-computer interface technology to human-machine systems in general. Journal of Neural Engineering 8(2): 025005. doi:10.1088/17412560/8/2/025005.

72. Zander, Thorsten O., Christian Kothe, Sabine Jatzev, and Matti Gaertner. 2010. Enhancing human-computer interaction with input from active and passive brain-computer interfaces. In Brain-Computer Interfaces, ed. D.S. Tan and A. Nijholt, 181199. Human-Computer Interaction Series: Springer London. 